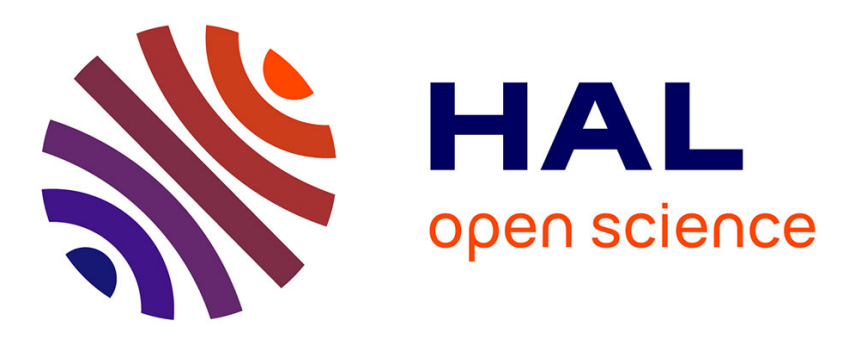

\title{
Vertical integration as a source of hold-up: An experiment
}

Marie-Laure Allain, Claire Chambolle, Patrick Rey, Sabrina Teyssier

\section{To cite this version:}

Marie-Laure Allain, Claire Chambolle, Patrick Rey, Sabrina Teyssier. Vertical integration as a source of hold-up: An experiment. European Economic Review, 2021, 137, pp.103783. 10.1016/j.euroecorev.2021.103783 . hal-03341440

\author{
HAL Id: hal-03341440 \\ https://hal.science/hal-03341440
}

Submitted on 14 Sep 2021

HAL is a multi-disciplinary open access archive for the deposit and dissemination of scientific research documents, whether they are published or not. The documents may come from teaching and research institutions in France or abroad, or from public or private research centers.
L'archive ouverte pluridisciplinaire HAL, est destinée au dépôt et à la diffusion de documents scientifiques de niveau recherche, publiés ou non, émanant des établissements d'enseignement et de recherche français ou étrangers, des laboratoires publics ou privés. 


\title{
Vertical Integration as a Source of Hold-up: an Experiment*
}

\author{
Marie-Laure Allain†, Claire Chambolle; Patrick Reył, and Sabrina Teyssier
}

May 12, 2021

\begin{abstract}
In a vertical chain in which two rivals invest before contracting with one of two competing suppliers, vertical integration can create hold-up problems for the rival. We develop an experiment to test this theoretical prediction in a setup in which suppliers can either pre-commit ex ante to being greedy or degrade ex post the input they provide to their customer. Our experimental results confirm that vertical integration creates hold-up problems. However, vertical integration also generates more departures from theory, which can be explained by bounded rationality and social preferences.
\end{abstract}

Keywords: Vertical Integration, Hold-up, Experimental Economics, Bounded Rationality, Social Preferences.

JEL Classification: C91, D90, L13, L41, L42.

*We thank two anonymous referees and the associate editor, Hans Theo Normann and Emmanuel Dechenaux, as well as participants to the ANR-DFG Workshop (2015), EARIE 2016 and 2017 Bergen Competition Policy Conference for helpful comments. We thank Sri Srikandan, who developed the z-tree programs, and Pascale Bazoche for her help in running the experiments. We gratefully acknowledge support from the Agence Nationale de la Recherche (ANR) and the Deutsche Forschungsgemeinschaft (DFG) for the French-German cooperation project "Competition and Bargaining in Vertical Chains", from the European Research Council under the Grant Agreement no. 340903, and from the ANR Investissements d'Avenir program under the grants ANR-11-IDEX-0003/Labex Ecodec/ANR-11-LABX-0047 and CHESS ANR-17EURE-0010.

${ }^{\dagger}$ CREST, CNRS, Ecole Polytechnique, Institut Polytechnique de Paris, Palaiseau, France; email: marielaure.allain@polytechnique.edu.

$\ddagger$ Université Paris-Saclay, INRAE, UR ALISS, 94205, Ivry-sur-Seine, France; CREST, Institut Polytechnique de Paris; claire.chambolle@inrae.fr

§Toulouse School of Economics, University Toulouse Capitole, Toulouse, France; email: patrick.rey@tsefr.eu.

IUniv. Grenoble Alpes, INRAE, CNRS, Grenoble INP, GAEL, 38000 Grenoble, France; email: sabrina.teyssier@inrae.fr. 


\section{Introduction}

The risk of expropriation of investment benefits, known as the hold-up problem, has long been recognized as an important source of under-investment (see Williamson, 1975, 1985. Klein, Crawford and Alchian, 1978). In response, the literature has emphasized the role of vertical integration as a solution to this problem (see Grossman and Hart, 1986). In a recent paper, however, Allain, Chambolle and Rey 2016 - henceforth ACR - point out that vertical integration can also create hold-up concerns ... for rivals. This paper develops a lab experiment which provides a test of this theory.

In $\mathrm{ACR}$, two downstream firms must invest before securing a key input from one of two upstream suppliers. The investment generates a return, which is reduced if the rival also invests. The upstream firms offer revenue-sharing contracts and investing is profitable for a downstream firm only if it receives a high enough share. Two market structures are considered: under vertical separation, all firms are independent; under (partial) vertical integration, two are vertically integrated and two are independent. Three variants of this model are studied. In the baseline variant, Bertrand competition leads the suppliers (integrated or not) to offer the highest revenue share; anticipating this, the downstream firms invest (no hold-up). The other two variants introduce hold-up options. In the commitment variant, suppliers have the option to commit to being greedy by demanding ex ante a large revenue share, that is, before downstream firms invest. In the sabotage variant, suppliers have the option to degrade ex post the quality provided to the downstream firm. An integrated supplier exerts either of these options, thus creating a hold-up problem for the independent firm which discourages its investment. Without integration, there is no hold-up problem because suppliers do not exert these options then. 
To test these theoretical predictions we ran a lab experiment designed to satisfy the key modelling assumptions. Three treatments, reflecting the three variants, were played first under separation and then under integration. To expedite the decision process, we simplified the setup as follows. First, we replaced the possibly integrated downstream firm by an automaton, behaving as predicted by theory; this left us with three players: a potentially integrated supplier and two independent firms (one upstream and one downstream). Second, in the Commitment and Sabotage treatments, we introduced the holdup option only for the potentially integrated supplier ${ }^{1}$ Finally, we discretized the set of sharing rules. ${ }^{2}$

The experimental results give support to the theoretical predictions: vertical integration indeed creates hold-up in the Commitment and Sabotage treatments. Specifically, under vertical integration, downstream players invest less often and receive a lower share of revenue; this is primarily driven by $U_{A}{ }^{\prime}$ s actual commitment decision in the former treatment, and by the threat of sabotage in the latter. The predictions of ACR thus survive the presence of inevitable noise stemming from bounded rationality, behavioral biases, social interactions or other sources. Furthermore, the observed departures in individual decisions in the Commitment and Sabotage treatments can be rationalized by bounded rationality and social preferences. This leads us to conclude that the mechanism highlighted by the model appears sufficiently robust to be empirically relevant.

The key ingredients and mechanisms of ACR echo actual antitrust cases. Commitment can be achieved in practice in various ways, e.g., by designing an input in such a way that it becomes of no use for downstream competitors,,$^{3}$ or by delegating the monetiza-

\footnotetext{
${ }^{1}$ In ACR, the independent supplier could also exert this option but never does so.

${ }^{2}$ In ACR, any sharing rule could be offered. To limit the emergence of cooperative strategies, we maintained a substantial number of options.

${ }^{3}$ See Avenel and Barlet (2000) for an example in the pulp and paper industry or Church and Gandal (2000) and Choi and Yi 2000) for examples in the software-hardware industry.
} 
tion of (part of) a patent portfolio to so-called "patent trolls", which aggressively enforce patent rights and litigate infringements. A case in point is provided by Microsoft's vertical integration in the downstream market for mobile devices. Right after its acquisition of Nokia's handset business in 2014, Microsoft delegated to Mosaid (now Conversant) the management of a portfolio of patents reading on such devices, prompting claims of patent trolling by rival device maker Huawei. This led the Chinese competition authority to impose behavioral remedies in order to prevent Microsoft from using its patents rights to restrict competition in the smartphone market..$^{4}$

Sabotage can correspond in practice to degrading the quality of an input or service supplied to competitors, but also to delaying competitor's access to new features or to abusing commercially sensitive information (see, e.g., Beard, Kaserman and Mayo, 2001; Mandy and Sappington, 2007). Such sabotage concerns were for example at the core of the policy debate prompted by the 2008 merger between TomTom, the leading manufacturer of portable navigation devices (or "PNDs"), and Tele Atlas, one of the two main providers of digital map databases. $5^{5}$

The experimental approach is particularly useful for testing the implications of vertical integration, which in practice is an endogenous decision prompted by various factors..$^{6}$ The controlled environment provided by lab experiments allows us instead to introduce a single exogenous change at a time. Relying on lab experiments is particularly useful

\footnotetext{
${ }^{4}$ Distributing a portfolio of complementary patents among several patent trolls would create double marginalization problems and lead to even higher royalty rates. In a recent dispute, Cisco accuses Ericsson, with which it competes on network equipment products, of having split the management of patents reading on these products between two patent trolls, Rockstar and Spherix, so as to raise total licensing fees. See Spherix Incorporated and NNPT, LLC versus Cisco Systems, in the US District Court for the District of Delaware, C.A. No. 14-393, Cisco Systems, Inc's Answer and Amended Counterclaims.

${ }^{5}$ Specifically, rival PND makers expressed concerns of sabotage through degraded map database, delayed access to new features, and leakages of commercially sensitive information (estimated sales, product roadmaps and new features). See the EC Decision of 14/05/2008 in Case No. COMP/M.4854 - TOMTOM/TELE ATLAS, at $\$ 190$.

${ }^{6}$ For a more general discussion on the experimental test of theories applied to competition policy, see Hinloopen and Normann 2009.
} 
also in the absence of field data. This is indeed the case here, as the key variables include specific investments, which are rarely observable, and upstream contracting terms, which constitute sensitive business secrets and are notoriously difficult to obtain $]^{7}$ Finally, we note that in the lab, subjects and professionals exhibit largely similar behaviors (see, e.g., Ball and Cech, 1996, Fréchette, 2015, Smith, Suchanek and Williams, 1988).

Two other mechanisms through which vertical integration can harm independent rivals are supplier opportunism (Hart and Tirole, 1990) and raising rivals' costs Ordover, Saloner and Salop, 1990, Salinger, 1988). The first one, which relies on secret contracting, has been experimentally validated by Martin, Normann and Snyder (2001). The second one relies in theory on a commitment to stop supplying or limit rivals' access. Yet, Normann (2011) finds in an experiment that vertical integration raises a rival's cost even without such commitment; he moreover shows that this is in line with a quantal response equilibrium, in which players do not best-respond with probability one, but choose better responses more frequently. We contribute to this literature by testing and validating a third mechanism through which vertical integration can harm independent rivals, namely, the hold-up problem highlighted by ACR. ${ }^{8}$ We also contribute to the experimental literature on hold-up, which has focused so far on bilateral settings - one player invests, and must then share the return with the other player. $9^{9}$ To test the predictions of ACR, we consider instead an extended setting in which each player faces competition.

This paper is organized as follows. Section 2 describes the experimental design and

\footnotetext{
${ }^{7}$ On the advantages of lab experiments for testing competition policy, see, e.g., Brandts and Potters (2018), Camerer and Weber (2013), Camerer 2015), Falk and Heckman (2009), Normann and Ricciuti (2009), Plott (1982, 1989).

Götte and Schmutzler 2009) present a rather large experimental literature on horizontal mergers; by contrast, the literature on vertical mergers is scarce.

${ }^{9}$ For example, Ellingsen and Johannesson (2004) analyze the impact of communication on hold-up; Sloof, Oosterbeek and Sonnemans (2007) study instead the role of investment observability, whereas Hoppe and Schmitz (2011) focus on the effect of contract renegotiation, and Dufwenberg, Smith and Van Essen (2013) consider the role of rights of control and vengeance.
} 
procedures. Section 3 reports the results on investment, sharing and hold-up decisions. Section 4 provides concluding remarks.

\section{The experiment}

We now present the three experimental treatments used to reflect the variants of ACR: Baseline, Commitment and Sabotage. We first detail the experimental design and equilibrium outcome, before presenting the experimental procedures.

\subsection{Experimental design}

There are three players, $U_{A}, U_{B}$ and $D:^{10}$ The downstream firm $D$ competes with an automaton $(\hat{D})$ and must decide whether to invest before selecting an upstream supplier, $U_{A}$ or $U_{B}$. The investment decision determines the revenue generated by the partnership. In each treatment, two market structures are considered, which affect the suppliers' payoffs: vertical separation (VS) and vertical integration (VI), where $U_{A}$ is integrated with $\hat{D}{ }^{11}$

\subsubsection{Baseline treatment}

Timing. In the Baseline treatment, the timing is as follows:

Stage 1: D decides whether to invest; her decision, $I \in\{0,1\}$, is publicly observed.

Stage 2: $U_{A}$ and $U_{B}$ simultaneously offer a revenue-sharing rule; the share $s$ left to

$D$ is chosen in $\mathcal{S} \equiv\{50 \% ; 55 \% ; 60 \% ; 65 \% ; 70 \% ; 75 \% ; 80 \% ; 85 \% ; 90 \%\}{ }^{12}$

\footnotetext{
${ }^{10}$ For the sake of neutrality, in the experiment the players were referred to as " $A$ " $\left(U_{A}\right)$, " $B$ " $\left(U_{B}\right)$, and " $C$ " $(D)$. For exposition purposes, we will use "he" for $U_{A}$ and $U_{B}$, and "she" for $D$.

${ }^{11}$ The automaton is assumed to behave as predicted by theory; it is not mentioned to the players and is only used to determine the payoff structure.

${ }^{12}$ To ensure equilibrium uniqueness, we limited the maximal share to $90 \%$. If suppliers could offer a share of $100 \%$, two equilibria would exist under vertical separation: one in which suppliers offer $100 \%$ and
} 
Stage 3: Having observed both offers, $D$ selects her partner.

Payoffs. The payoffs correspond to a market game in which $D$ 's investment increases her revenue but reduces $\hat{D}$ 's revenue. The two suppliers, $U_{A}$ and $U_{B}$, compete by offering revenue-sharing contracts. Under VS, $\hat{D}$ automatically selects the same supplier as $D{ }^{13}$ Under VI, $\hat{D}$ is integrated with $U_{A}$; it is thus supplied internally and its revenue goes to $U_{A}$.

Specifically, $D$ 's investment, $I \in\{0,1\}$, generates a revenue $r(I)=(0.3+0.7 \times$ $I)(97.1-23.1 \times I)$ for $D$ and a revenue $\hat{r}(I)=97.1-23.1 \times I$ for $\hat{D}{ }^{14} D$ bears a cost equal to $4.5+31.5 \times I$, whereas $\hat{D}$ bears a cost of $45 .{ }^{15}$ Table 1 presents the resulting costs and revenues (in euros):

Table 1: Costs and revenues in the Baseline treatment

\begin{tabular}{|c|c|c|c|c|c|}
\hline$D^{\prime}$ 's investment & $D^{\prime}$ 's cost & $\begin{array}{c}\text { Revenue } \\
\text { generated by } D\end{array}$ & $\hat{D}^{\prime}$ 's cost & $\begin{array}{c}\text { Revenue } \\
\text { generated by } \hat{D}\end{array}$ & $\begin{array}{c}\text { Total } \\
\text { revenue }\end{array}$ \\
\hline$I=0$ & 4.5 & 29.13 & 45 & 97.1 & 126.23 \\
$I=1$ & 36 & 74 & 45 & 74 & 148 \\
\hline
\end{tabular}

We now describe the (rounded) payoffs presented to the subjects. Table 2 reports $D^{\prime}$ s payoff, which is the same under VS and VI: it is equal to her share $s$ of the revenue she generates, net of her cost. For any given investment decision, D's payoff increases with the share obtained. Investing is profitable as long as the share $s$ is large enough, namely, obtain zero profit, and another one in which they offer the next-best share and receive a positive expected profit. Likewise, if suppliers could offer a share of $95 \%$, there would exist two equilibria, $(90 \%, 90 \%)$ and $(95 \%, 95 \%)$.

${ }^{13}$ In ACR, under VS, the downstream firms have the same objective and thus pick the cheaper supplier; when the suppliers offer the same terms, assuming that the downstream firms select the same one does not affect the equilibrium outcomes.

${ }^{14}$ The revenue functions $r(I)$ and $\hat{r}(I)$ are derived from a symmetric function presented in ACR, of the form $r\left(I_{i}, I_{j}\right)=\left(0.3+0.7 \times I_{i}\right)\left(120.2-23.1 \times\left(I_{i}+I_{j}\right)\right)$, where $I_{i}$ and $I_{j}$ refer to the investments of $D$ and $\hat{D}$, and it is a dominant strategy for $\hat{D}$ to invest; we thus assume here that $\hat{D}$ indeed invests.

${ }^{15}$ Even when she invests, $D^{\prime}$ s cost is lower than $\hat{D}^{\prime}$ s (36 instead of 45$)$. This cost difference does not alter the equilibrium outcome, but limits the payments made to $U_{A}$ subjects, by reducing the additional payoffs presented in Table 5 
above $s^{*} \equiv 70 \% 16$

Table 2: Payoff of $D$ in the Baseline treatment under VS and VI

\begin{tabular}{|c|ccccccccc|}
\hline$S$ & $50 \%$ & $55 \%$ & $60 \%$ & $65 \%$ & $70 \%$ & $75 \%$ & $80 \%$ & $85 \%$ & $90 \%$ \\
\hline$I=0$ & 10 & 12 & 13 & 14 & 16 & 17 & 19 & 20 & 22 \\
$I=1$ & 1 & 5 & 8 & 12 & 16 & 20 & 23 & 27 & 31 \\
\hline
\end{tabular}

We now turn to the payoff of the supplier selected by $D$, which depends on the market structure. Table 3 reports the payoff under VS, equal to a share $1-s$ of the total revenue generated by the two downstream firms, which is larger if $D$ invests (148 instead of 126.23, as shown in Table 1).

Table 3: Payoff of the selected supplier in the Baseline treatment under VS

\begin{tabular}{|c|ccccccccc|}
\hline$s$ & $50 \%$ & $55 \%$ & $60 \%$ & $65 \%$ & $70 \%$ & $75 \%$ & $80 \%$ & $85 \%$ & $90 \%$ \\
\hline$I=0$ & 63 & 57 & 50 & 44 & 38 & 32 & 25 & 19 & 13 \\
$I=1$ & 74 & 67 & 59 & 52 & 44 & 37 & 30 & 22 & 15 \\
\hline
\end{tabular}

Under VI, the selected supplier receives a share $1-s$ of the revenue generated by $D$ (29.13 if $D$ does not invest and 74 if $D$ invests, as shown in Table 1 ), as reported in Table 4.

Table 4: Payoff of the supplier selected by $D$ in the Baseline treatment under VI

\begin{tabular}{|c|ccccccccc|}
\hline$S$ & $50 \%$ & $55 \%$ & $60 \%$ & $65 \%$ & $70 \%$ & $75 \%$ & $80 \%$ & $85 \%$ & $90 \%$ \\
\hline$I=0$ & 15 & 13 & 12 & 10 & 9 & 7 & 6 & 4 & 3 \\
$I=1$ & 37 & 33 & 30 & 26 & 22 & 19 & 15 & 11 & 7 \\
\hline
\end{tabular}

In addition, irrespective of $D^{\prime}$ s choice of supplier, the integrated $U_{A}$ receives the profit generated by his downstream subsidiary $\hat{D}$, which is adversely affected by $D^{\prime}$ s investment, as reflected in Table $5^{17}$ As a result, while $U_{B}$ 's payoff remains larger when $D$ invests, $U_{A}$ 's total payoff (even if selected by $D$ ) is instead lower when $D$ invests.

\footnotetext{
${ }^{16}$ The particular value of $s^{*}$ does not matter as long as it remains strictly within the interval of feasible shares (that is, between $55 \%$ and $85 \%$ ).

${ }^{17}$ The profit generated by $\hat{D}$ amounts to $74-45=29$ if $D$ invests, while it amounts to $97.1-45=52.1$ if $D$ does not invest.
} 
Table 5: Payoff for $U_{A}$ generated by the subsidiary in the Baseline treatment under VI

$$
\begin{array}{|l|l|}
\hline I=0 & 52 \\
I=1 & 29 \\
\hline
\end{array}
$$

Finally, to avoid biases against actions that may generate negative profits (see Dufwenberg et al., 2007), suppliers obtain a fixed payment $f=2$ in case they are not selected.18

Equilibrium outcomes. Under both VS and VI, for any given investment decision made in stage 1, in stage 2 the suppliers compete to be selected by $D$, and this competition induces them to offer the maximum share, that is, $90 \%$. It follows that $D$ is indifferent between the two suppliers in stage 3 and, as $90 \%>s^{*}, D$ invests in stage 1: there is no hold-up.

\subsubsection{Commitment treatment}

Timing. In the Commitment treatment, an ex ante stage 0 is added to the Baseline game, in which $U_{A}$ can commit himself to being "greedy". Specifically, in this stage 0, which takes place before investment decisions, $U_{A}$ can commit himself, if he wishes so, to offering the lowest share $50 \%$ to $D 1^{19}$ The three stages of the Baseline game are then played, with the caveat that, in stage $2, U_{A}$ does not make any choice if he already committed himself in stage 0 .

Payoffs. Using the commitment option costs 5. All payoffs are otherwise the same as in the Baseline treatment.

\footnotetext{
${ }^{18}$ Not granting this payment to the selected suppliers reduces the financial cost of the experiment without affecting the equilibria.

${ }^{19}$ Alternatively, $U_{A}$ could commit to any other share strictly lower than $s^{*}$, thus discouraging $D$ 's investment.
} 
Equilibrium outcomes. Under VS, $U_{A}$ never uses the commitment option, as this would put him at a disadvantage in the competition stage and is costly. Therefore, the outcome is the same as in the Baseline treatment: the suppliers offer the maximal share $90 \%$ to $D$ who invests.

Under VI, however, $U_{A}$ benefits from $D$ deciding not to invest, as this increases the additional payoff displayed in Table 5. Specifically, by committing himself in stage 0 to leaving $50 \%, U_{A}$ confers market power to $U_{B}$ who, in stage 2 , offers $D$ the lowest share exceeding 50\%, namely 55\%; anticipating this, $D$ does not invest in stage 1 , as $55 \%<s^{*}$. This gives $U_{A}$ a profit of 52 through his subsidiary and a profit of 2 from not being selected by $D ; U_{A}$ 's net payoff is therefore $52+2-5=49$. By not committing himself, $U_{A}$ would instead obtain 29 from his downstream subsidiary and at most 7 from the competition for supplying $D$ (as both suppliers offer $90 \%$ ), which only amounts to 36 . It is thus optimal for $U_{A}$ to commit in stage 1 under VI.

Hence, in this Commitment treatment, vertical integration creates hold-up problems for $D$, who does not invest.

\subsubsection{Sabotage treatment}

Timing. The Sabotage treatment adds an ex post stage 4 to the Baseline game, in which, if selected by $D, U_{A}$ chooses whether or not to sabotage his supply to $D{ }^{20}$ Specifically, in this stage 4 , which takes place after the supplier selection decision, if selected, $U_{A}$ can exert an option " $\mathrm{S}$ "; exerting this option reduces $D$ 's revenue to an extent that discourages her investment ${ }^{21}$ but increases the profit of $U_{A}$ 's downstream subsidiary under VI.

\footnotetext{
${ }^{20}$ The word "sabotage" is never mentioned in the experiment, because its negative connotation could influence the subjects.

${ }^{21}$ That is, what matters is that $D$ then obtains a revenue that is lower than the revenue that would otherwise be generated by a share $s^{*}$.
} 
Payoffs. Using the sabotage option costs 5 and yields a payoff for $D$ given by Table $6{ }^{22}$ Under VI, it brings an additional benefit 10 to $U_{A}{ }^{\prime}$ s downstream subsidiary. ${ }^{23}$

Table 6: Payoff of $D$ in the Sabotage treatment if she selects $U_{A}$ who then uses option $S$

$$
\begin{array}{|c|c|}
\hline I=0 & 11 \\
I=1 & 3 \\
\hline
\end{array}
$$

The payoffs of all players are otherwise the same as in the Baseline treatment.

Equilibrium outcomes. Under VS, the option $S$ involves a cost and no benefit; hence, $U_{A}$ never uses it, and the outcome remains as in the Baseline treatment: the suppliers offer the maximal share $90 \%$ to $D$, who invests.

By contrast, under VI, $U_{A}$ has an incentive to use the option $S$, as this brings a net benefit $10-5>0$. As a result, regardless of the offer made by $U_{A}$ and of $D^{\prime}$ s investment decision, $U_{B}$ wins the competition by offering the lowest share leaving $D$ a higher payoff than that displayed in table 6, which is $55 \%$. Anticipating this, $D$ does not invest in stage 1 , as $55 \%<s^{*}$. Note that, formally, there are multiple equilibria, which only differ in the offer initially made by $U_{A}$ : indeed, offering any share constitutes an equilibrium strategy.

Hence, in this Sabotage treatment, vertical integration creates hold-up problems for $D$, who does not invest.

\subsubsection{Recap}

Table 7 summarizes the theoretical predictions for each treatment.

\footnotetext{
${ }^{22}$ This payoff is based on an effective share of $52.5 \%$, which enables $U_{B}$ to win the competition with a $55 \%$ share.

${ }^{23}$ Note that varying these cost and benefit does not affect the equilibrium outcome as long as the cost does not exceed the benefit.
} 
Table 7: Theoretical predictions for all treatments and market structures

\begin{tabular}{|c|c|c|c|c|c|}
\hline Treatment & Market structure & Stage & Player & Action & Payoff \\
\hline \multirow{3}{*}{ Baseline } & \multirow{3}{*}{ VS and VI } & 1 & $D$ & invests & \\
\hline & & 2 & $U_{A} ; U_{B}$ & $90 \% ; 90 \%$ & $15 ; 2^{\mathrm{a}}$ \\
\hline & & 3 & $D$ & $U_{A}$ or $U_{B}$ & 31 \\
\hline \multirow{8}{*}{ Commitment } & \multirow{4}{*}{ VS } & 0 & $U_{A}$ & does not commit & \\
\hline & & 1 & $D$ & invests & \\
\hline & & 2 & $U_{A} ; U_{B}$ & $90 \% ; 90 \%$ & $15 ; 2^{\mathrm{a}}$ \\
\hline & & 3 & $D$ & $U_{A}$ or $U_{B}$ & 31 \\
\hline & \multirow{4}{*}{ VI } & 0 & $U_{A}$ & commits to $50 \%$ & \\
\hline & & 1 & $D$ & does not invest & \\
\hline & & 2 & $U_{A} ; U_{B}$ & [no decision] ; 55\% & $54 ; 13$ \\
\hline & & 3 & $D$ & $U_{B}$ & 12 \\
\hline \multirow{8}{*}{ Sabotage } & \multirow{4}{*}{ VS } & 1 & $D$ & invests & \\
\hline & & 2 & $U_{A} ; U_{B}$ & $90 \% ; 90 \%$ & $15 ; 2^{\mathrm{a}}$ \\
\hline & & 3 & $D$ & $U_{A}$ or $U_{B}$ & 31 \\
\hline & & 4 & $U_{A}$ (if selected) & does not use $S$ & \\
\hline & \multirow{4}{*}{ VI } & 1 & $D$ & does not invest & \\
\hline & & 2 & $U_{A} ; U_{B}$ & any $s \in \mathcal{S} ; 55 \%$ & $54 ; 13$ \\
\hline & & 3 & D & $U_{B}$ & 12 \\
\hline & & 4 & $U_{A}$ (if selected) & uses $\mathrm{S}$ & \\
\hline
\end{tabular}

a The first number is the payoff of the supplier selected by $D$.

\subsection{Experimental procedures}

We now describe the organization of the experimental sessions. Each session is dedicated to one treatment, first played for ten periods under vertical separation (phase VS), followed by ten periods under vertical integration (phase VI). Each subject participates in only one session (but plays both phases). Thirty subjects are active in each session: 10 for $U_{A}, 10$ for $U_{B}$, and 10 for $D$.

At the beginning of each session, the instructions (see Online Appendix A) are given to the participants and read aloud. They include tables describing the payoffs resulting from the three players' strategies. These payoff tables are therefore common knowledge. Each subject is then randomly assigned a role $\left(U_{A}, U_{B}\right.$ or $\left.D\right)$ and keeps the same role for the whole session.

At the beginning of each period, groups of 3 subjects are constituted; these three sub- 
jects interact during that period and no communication is allowed between them. In order to limit the scope for repeated interaction, we use a perfect stranger matching protocol between $U_{A}$ and $U_{B}$, ensuring that these subjects meet only once within each phase; in each period, each $D$ subject is then randomly matched with a couple of $U_{A}$ and $U_{B}$ subjects.

Within a group, subjects observe all prior decisions before making their next decisions, ${ }^{24}$ and a recap is provided to the group at the end of the period. At the end of each period, each subject learns his or her own payoff for that period. At the end of the twenty periods, one period is randomly chosen, and each subject earns the payoff obtained in that period.

At the end of each session, subjects are asked to answer a series of questions about their age, sex and occupation; they are also asked to situate themselves on a 0 to 10 risk-aversion scale ranging from "ready to take risks" to "not ready to take risks at all" (Dohmen et al. 2005). Finally, they are asked to answer three standard questions; the number of correct answers is then used as an IQ score (from 0 to 3). ${ }^{25}$

We conducted nine sessions (three per treatment) at Ecole Polytechnique in Paris, from April 2015 to April 2017. In total, 270 subjects participated. The sessions lasted between 90 and 120 minutes, including time for instructions. On average, subjects earned 25.18 euros (including a show-up fee of 5 euros). The experiments were programmed using the software z-tree (Fischbacher, 2007). The subjects included both students (undergraduate and graduate students in engineering), and employees. $26.32 \%$ were female (41\% in

\footnotetext{
${ }^{24}$ The only exception concerns the Sabotage treatment, in which, when selected, $U_{A}$ does not observe the share offered by $U_{B}$ before deciding whether to exert the option $S$. This, however, has no impact on the predicted behavior.

${ }^{25}$ See Appendix A for more details on the IQ questionnaire.

${ }^{26}$ An additional session has been conducted for each of the Commitment and Sabotage treatments. However, due to schedule constraints, these two sessions differed from the others in terms of percentage of students and IQ level. For reliability purposes, we dropped the session with an average IQ of 2.57 for the Commitment treatment and of 1.20 for the Sabotage treatment, which correspond to the two extreme values
} 
the Baseline treatment, 30\% in the Commitment treatment and 26\% in the Sabotage treatment) and $32 \%$ were employees (40\% in the Baseline treatment, $28 \%$ in the Commitment treatment and $29 \%$ in the Sabotage treatment). The average answer to the question on risk-aversion is 5.75 (5.58 in the Baseline treatment, 5.96 in the Commitment treatment, and 5.72 in the Sabotage treatment). Finally, the average IQ is 1.94 (1.65 in the Baseline treatment, 2.13 in the Commitment treatment, and 2.04 in the Sabotage treatment).

Most of the students at Ecole Polytechnique are male (in our sample, 21\% of students are female, whereas $56 \%$ of employees are female); hence, gender and occupation (student or employee) are highly correlated (and occupation is itself highly correlated with age) ${ }^{27}$ We also observe that IQ is highly correlated with these two variables (Pearson correlation tests are presented in appendix B). In our analysis, we have chosen to control for the individuals' IQ level (which has a broader range than the binary variables). When using a Mann-Whitney ranksum test, we observe significant differences between the Baseline treatment and each of the Commitment and Sabotage treatments $(p<0.05)$, but no difference between the Commitment and Sabotage treatments $(p=0.5691)$. However, when using a Kolmogorov-Smirnov test, the IQ is not significantly different across the three treatments. Finally, no significant difference in risk-aversion is observed across the three treatments (using both a Mann-Whitney ranksum test and a Kolmogorov-Smirnov test).

\section{Results}

We now study the impact of vertical integration on subjects' decisions. In Section 3.1, we show that, as predicted by theory, vertical integration creates hold-up problems in the Commitment and Sabotage treatments. We also observe some departures from theory, among all sessions. Including these two sessions does not affect the qualitative results.

${ }^{27}$ Students are aged between 18 and 27. 
which, interestingly, are exacerbated under vertical integration in the Commitment and Sabotage treatments. In Section 3.2, we show that these departures can be explained by classic behavioral biases, namely, bounded rationality and social preferences.

\subsection{Hold-up}

Figure 1 represents the evolution of the proportion of $D$ subjects who invest. In the vertical separation phase (VS hereafter, corresponding to the first ten periods), the three treatments generate similar investments: about $82 \%$ of $D$ subjects invest in the Baseline treatment and Commitment treatments, and $92 \%$ in the Sabotage treatment. In the vertical integration phase (VI hereafter, last ten periods), this proportion remains about the same in the Baseline treatment (90\%). By contrast, this proportion drops substantially in the Sabotage treatment (to 52\%) and, to a larger extent, in the Commitment treatment (to $32 \%)$.

Figure 1: Evolution of investment

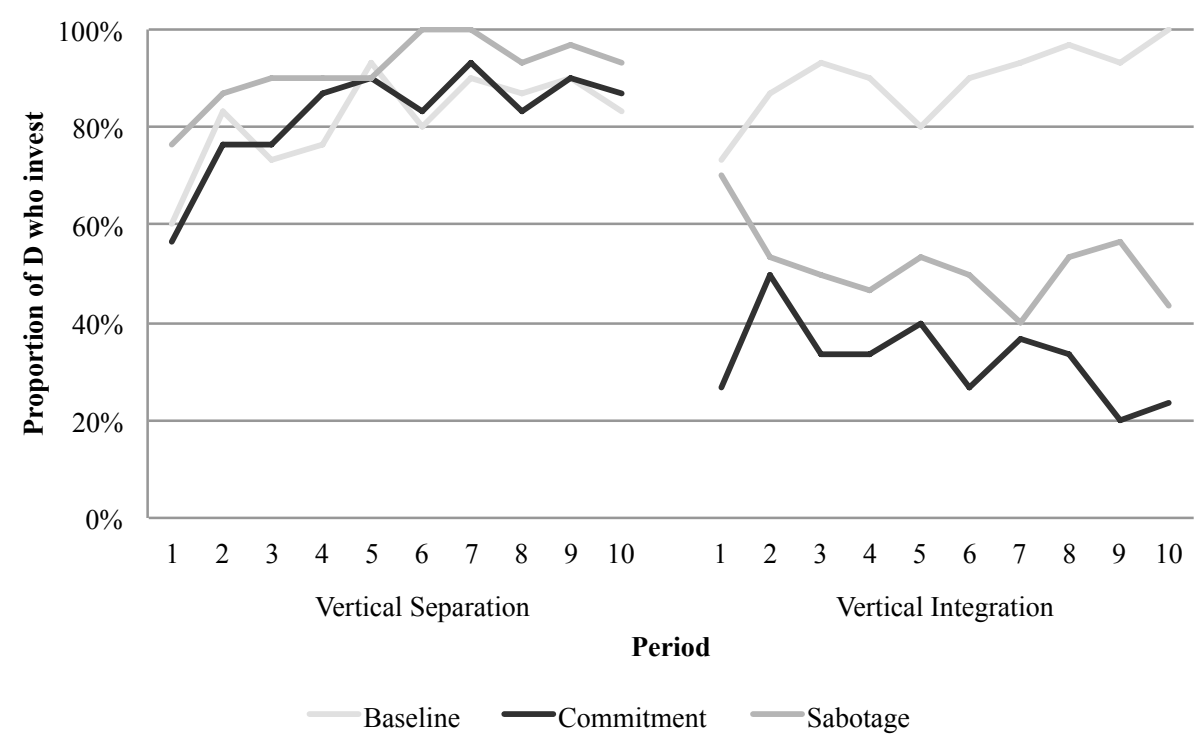

Similar patterns arise for the evolution of the shares offered and accepted (see Figures 2 and 3 in Appendix C). The average shares offered by the suppliers, which range from 
$80 \%$ to $84 \%$ under VS in the three treatments, remain in that range in the Baseline treatment under VI; by contrast, the share offered by $U_{B}$ drops in the Sabotage treatment (to $68 \%$ ), and the shares offered by both suppliers drop to an even larger extent in the Commitment treatment (to $58 \%$ for $U_{A}$ and $62 \%$ for $U_{B}$ ) ${ }^{28}$ Likewise, the average accepted share, which is about $85 \%$ under VS, remains about the same under VI in the Baseline treatment (86\%); it drops instead substantially in the Sabotage treatment (to $75 \%$ ), and even more so in the Commitment treatment (to $64 \%$ ).

These patterns support the theoretical predictions: vertical integration has no effect in the Baseline treatment, but generates hold-up problems in the Commitment and Sabotage treatments. This is confirmed by Table 8 , which reports the marginal effect of vertical integration, for each treatment, on the investment decisions as well as on the shares offered and accepted $2^{29}$ In the Baseline treatment, vertical integration does not reduce investment; it actually appears to become slightly higher, which may reflect a learning effect, as the observed behavior gets closer to the prediction. By contrast, vertical integration reduces the probability of investment in the other two treatments, by $43 \%$ in the Commitment treatment and by $37 \%$ in the Sabotage treatment.

Regarding the shares offered and accepted, the results are also in line with theory. There is no significant effect in the Baseline treatment. By contrast, vertical integration significantly reduces the shares offered by both suppliers in the Commitment treatment and the share offered by $U_{B}$ in the Sabotage treatment. This results in a negative marginal

\footnotetext{
${ }^{28}$ Recall that, in the Sabotage treatment, there is no theoretical prediction about the share offered by $U_{A}$.

${ }^{29}$ In tables 8 to 13 , for binary variables, we use Probit regressions and compute average marginal effects: we first compute the marginal effect for each subject, before aggregating across subjects; see Williams (2012) for details of the method. For the shares offered and accepted, we use OLS regressions. All regressions control for session fixed effects and, as subjects make repeated decisions during a session, we evaluate standard errors using clusters at the individual level.

We provide in the Online Appendix E robustness checks controlling for IQ and risk-aversion of the decision maker and/or of all three group subjects. We also check for learning effects by discarding the first two periods of each phase. Finally, we provide an additional check using clusters at the session level. In all cases, the results are qualitatively the same.
} 
effect on the share obtained by $D$, of -20 percentage points in the Commitment treatment and -10 percentage points in the Sabotage treatment.

Table 8: Marginal effect of vertical integration

\begin{tabular}{lccccc}
\hline \hline & Investment & $\begin{array}{c}\text { Share accepted } \\
\text { by } D\end{array}$ & $\begin{array}{c}\text { Share offered } \\
\text { by } U_{A}\end{array}$ & $\begin{array}{c}\text { Share offered } \\
\text { by } U_{B}\end{array}$ & $\begin{array}{c}U_{A}{ }^{\prime} \text { s hold- } \\
\text { up decision }\end{array}$ \\
\hline Baseline & $0.080^{* * *}$ & 0.600 & 0.983 & -1.183 & \\
& $(0.028)$ & $(0.553)$ & $(0.993)$ & $(1.056)$ & \\
Commitment & $-0.428^{* * *}$ & $-20.12^{* * *}$ & $-22.583^{* * *}$ & $-18.1^{* * *}$ & $0.481^{* * *}$ \\
& $(0.031)$ & $(1.282)$ & $(2.688)$ & $(1.416)$ & $(0.013)$ \\
Sabotage & $-0.367^{* * *}$ & $-10.45^{* * *}$ & 0.217 & $-13.633^{* * *}$ & $0.458^{* * *}$ \\
& $(0.055)$ & $(1.181)$ & $(1.100)$ & $(1.826)$ & $(0.021)$ \\
\hline
\end{tabular}

Notes: Standard errors are reported in parentheses. ${ }^{* * *}$ represents significance at $1 \%$ level.

These findings can be summarized as:

Result 1 (investment and sharing decisions). In line with theoretical predictions, vertical integration does not reduce investment and has no impact on the shares offered and accepted in the Baseline treatment; by contrast, vertical integration reduces investment as well as the shares offered and accepted in the Commitment and Sabotage treatments.

In the Commitment treatment, the impact of vertical integration is primarily driven by the proportion of $U_{A}$ subjects who choose to exert the hold-up option (i.e., to commit themselves to offering a 50\% share), which increases from $8 \%$ under VS to $72 \%$ under VI. This is confirmed by Table 8 , which reports that vertical integration has a marginal effect of $48 \%$ on the commitment decision. Table 9 moreover confirms that $U_{A}$ 's commitment decision is the key driver: under both VS and VI, it has a marginal effect of $-50 \%$ on $D^{\prime}$ s investment and of $-23 \%$ on the share offered by $U_{B}$.

In the Sabotage treatment, the impact of vertical integration is primarily driven by the threat of sabotage. Indeed, the proportion of $U_{A}$ subjects who choose the sabotage option when selected increases from $10 \%$ under VS to $78 \%$ under VI. Table 8 confirms 
Table 9: Marginal effect of $U_{A}{ }^{\prime}$ s commitment

\begin{tabular}{lc}
\hline \hline Investment & $-0.500^{* * *}$ \\
& $(0.015)$ \\
Share offered by $U_{B}$ & $-22.874^{* * *}$ \\
& $(1.666)$ \\
Share accepted by $D$ & $-28.502^{* * *}$ \\
& $(2.250)$ \\
\hline
\end{tabular}

Notes: The sample includes both VS and VI. Standard errors are reported in parentheses. ${ }^{* * *}$ represents significance at $1 \%$ level.

that vertical integration has a marginal effect of $46 \%$ on $U_{A}$ subjects' sabotage decisions when selected.

These findings can be summarized as:

Result 2 (hold-up decisions). In the Commitment treatment, the impact of vertical integration is primarily driven by $U_{A}$ 's actual commitment decision. In the Sabotage treatment, it is instead driven by the threat of Sabotage by $U_{A}$ if selected.

\subsection{Discussion}

Figure 1 shows that, as one may expect, subjects sometimes depart from predicted behavior. Interestingly, however, these departures are more frequent under vertical integration in the Commitment and Sabotage treatments. To explore this further, we build in Appendix $\mathrm{D}$ a binary deviation score for each decision. We find that vertical integration increases $U_{A}$ subjects' departures in hold-up decisions in the Commitment treatment: they do not exert hold-up as often as predicted. In the Sabotage treatment, it increases instead $U_{B}$ and $D$ subjects' departures: the supplier is too generous, the downstream firm invests too frequently, and the two departures are moreover correlated.

As the perfect stranger protocol used in the experiment limits the scope for cooperation based on repeated interactions, we explore in Appendix E Elternative approaches 
based on behavioral biases. We find that bounded rationality (namely, level- $k$ thinking) can explain why vertical integration creates departures in hold-up decisions in the Commitment treatment, where this decision comes first; $U_{A}$ must therefore anticipate the other subjects' subsequent decisions, which involves higher levels of thinking ${ }^{30}$ That $U_{A}$ subjects do not exert the hold-up option as often as predicted suggests that they may have social preferences ${ }^{31}$ preventing them from harming others (see Table 11 in Appendix D.1 32 We find that beliefs about such preferences can explain why vertical integration creates departures in $D$ and $U_{B}$ subjects' decisions in the Sabotage treatment where $U_{A}{ }^{\prime}$ s decision comes last, which exposes $D$ and $U_{B}$ to strategic uncertainty ${ }^{33}$ We develop a formal model which moreover explains the observed correlation between $D$ and $U_{B}$ subjects' departures: $D$ invests more often if she does not expect $U_{A}$ to exert his hold-up option and, as the investment decision reflects her beliefs, $U_{B}$ then offers more generous shares.

These findings can be summarized as:

Result 3 (departures from theory). Level-k thinking explains the observed departures in the Commitment treatment, where the hold-up decision comes first; social preferences explain instead these departures in the Sabotage treatment, where the hold-up decision comes last.

To conclude this discussion, we note that if bounded rationality or social preferences were less relevant for firms' managerial decisions than for lab subjects, we would expect even fewer departures from theory, thus reinforcing the prediction that vertical integration is a source of hold-up.

\footnotetext{
${ }^{30}$ Level- $k$ thinking consists in introducing an iterative decision process where players vary in their levels of thinking (Stahl, 1993: Nagel, 1995, Camerer, Ho and Chong, 2004). The process begins with "level-0" types who are not strategic and pick an arbitrary decision. "Level-1" players then best respond to "level-0" players, and so on.

${ }^{31}$ Models of social preferences (see, e.g., Falk and Fischbacher 2006) are supported by experimental tests showing the existence of such preferences among individuals (see, e.g., Charness and Rabin, 2002.

${ }^{32} \mathrm{VI}$ increases substantially the average deviation scores in both treatments, but this effect is significant only in the Commitment treatment, because $U_{A}$ is rarely selected in the Sabotage treatment.

${ }^{33}$ See, e.g., Van Huyck, Battalio and Beil (1990) and Heinemann, Nagel and Ockenfels 2009).
} 


\section{Conclusion}

ACR predicts that vertical integration creates hold-up problems for independent rivals, by giving the integrated firm an incentive to either commit itself ex ante to being greedy ("Commitment"), or degrade ex post the quality provided to independent customers ("Sabotage" $\mathrm{e}^{\prime}$. To test these theoretical predictions, we designed a laboratory experiment reflecting the key modelling assumptions.

The laboratory data support the predictions: vertical integration exacerbates hold-up concerns. Specifically, in the Commitment and Sabotage treatments, vertical integration reduces investment as well as the shares offered and accepted. This is primarily driven by the integrated supplier's actual commitment decision in the first treatment, and by the threat of sabotage in the other treatment. These results show that the mechanism highlighted by ACR resists the experimental noise and thus deserves further investigations.

The data also reveal some departures from theory, which are more pronounced for hold-up decisions in case of Commitment and for investment decisions and the contract terms offered by the independent supplier in case of Sabotage; the latter departures are moreover positively correlated. We find that bounded rationality (namely, level- $k$ theory) can explain the first pattern whereas the introduction of social preferences for the integrated supplier can instead explain the other patterns.

As for any empirical study, the robustness of the results with respect to changes in the modelling setup (e.g., the nature of the hold-up options, the competition model or the payoff structure) or in the experimental design is an important issue, which calls for additional tests using (field) experimental data or the analysis of "real-world" markets when possible. We leave this as an avenue for future research. 


\section{References}

Allain, M-L., C. Chambolle, and P. Rey. 2016. "Vertical Integration as a Source of Holdup." The Review of Economic Studies, 83(1): 1-25.

Avenel, E., and C. Barlet. 2000. "Vertical Foreclosure, Technological Choice, and Entry on the Intermediate Market." Journal of Economics E Management Strategy, 9(3): 211-230.

Ball, S. B., and P.-A. Cech. 1996. "Subject Pool Choice and Treatment Effects in Economic Laboratory Research." In Research in Experimental Economics. , ed. M. R. Isaac, Chapter 6, 239-292. Greenwich, CT: JAI Press.

Beard, T. Randolph, David L. Kaserman, and John W. Mayo. 2001. "Regulation, Vertical Integration and Sabotage." The Journal of Industrial Economics, 49(3): 319-333.

Brandts, J., and J. Potters. 2018. “Experimental Industrial Organization." In Handbook of Game Theory and Industrial Organization. , ed. L. C. Corchón and M. A. Marini, Chapter 17, 453-474. Edward Elgar Publishing Ltd.

Camerer, C. F. 2015. “The Promise and Success of Lab-Field Generalizability in Experimental Economics: A Critical Reply to Levitt and List." In Handbook of Experimental Economic Methodology. , ed. G. R. Fréchette and A. Schotter, Chapter 14, 249-296. Oxford University Press.

Camerer, C. F., and R. A. Weber. 2013. “Experimental Organizational Economics.” In Handbook of Organizational Economics. , ed. R. Gibbons and J. Roberts, Chapter 6, 213262. Princeton University Press.

Camerer, C.F., T. Ho, and J. Chong. 2004. "A cognitive hierarchy model of games." The Quarterly Journal of Economics, 119(3): 861-898. 
Charness, G., and M. Rabin. 2002. "Understanding Social Preferences with Simple Tests." Quarterly Journal of Economics, 117(3): 817-869.

Choi, Jay Pil, and Sang-Seung Yi. 2000. "Vertical Foreclosure with the Choice of Input Specifications." The RAND Journal of Economics, 31(4): 717-743.

Church, J., and N. Gandal. 2000. "Systems Competition, Vertical Merger, and Foreclosure." Journal of Economics E Management Strategy, 9(1): 25-51.

Dohmen, T., A. Falk, D. Huffman, U. Sunde, J. Schupp, and G. Wagner. 2005. "Individual Risk Attitudes: New Evidence from a Large, Representative, ExperimentallyValidated Survey." DIW Berlin Discussion Paper, 511.

Dufwenberg, M., A. Smith, and M. Van Essen. 2013. "Hold-up: with a vengeance." Economic Inquiry, 51(1): 896-908.

Ellingsen, T., and M. Johannesson. 2004. "Is there a hold-up problem?" Scandinavian Journal of Economics, 106(3): 475-494.

Falk, A., and J. J. Heckman. 2009. "Lab experiments are a major source of knowledge in the social sciences." Science, 326(5952): 535-538.

Falk, A., and U. Fischbacher. 2006. "A Theory of Reciprocity." Games and Economic Behavior, 54: 293-315.

Fischbacher, U. 2007. "z-Tree: Zurich toolbox for ready-made economic experiments." Experimental Economics, 10(2): 171-178.

Fréchette, G. R. 2015. “Laboratory Experiments: Professionals versus Students." In Handbook of Experimental Economic Methodology. , ed. G. R. Fréchette and A. Schotter, Chapter 17, 360-390. Oxford University Press. 
Götte, L., and A. Schmutzler. 2009. "Merger Policy: what can we learn from experiments?" In Experiments and Competition Policy. , ed. J. Hinloopen and H.-T. Normann, Chapter 8, 185-216. Cambridge University Press.

Grossman, S. J., and O. D. Hart. 1986. “The Costs and Benefits of Ownership: A Theory of Vertical and Lateral Integration." Journal of Political Economy, 94(1): 691-719.

Hart, O., and J. Tirole. 1990. "Vertical Integration and Market Foreclosure." Brookings Papers on Economic Activity. Microeconomics, 205-285.

Heinemann, F., R. Nagel, and P. Ockenfels. 2009. “Measuring Strategic Uncertaintly in Coordination Games." Review of Economic Studies, 76(1): 181-221.

Hinloopen, J., and H.-T. Normann. 2009. Experiments and Competition Policy. Cambridge University Press.

Hoppe, E. I., and P. W. Schmitz. 2011. “Can contracts solve the hold-up problem? Experimental evidence." Games and Economic Behavior, 73: 186-199.

Klein, B., G. Crawford, and A. Alchian. 1978. “Vertical Integration, Appropriable Rents, and the Competitive Contracting Process." Journal of Law and Economics, 21(2): 297-326.

Mandy, David M., and David E. M Sappington. 2007. “Incentives for sabotage in vertically related industries." Journal of Regulatory Economics, 31(3): 235-260.

Martin, S., H.T Normann, and C.M. Snyder. 2001. “Vertical foreclosure in experimental markets." RAND Journal of Economics, 32(3): 466-496.

McKelvey, Richard D., and Thomas R. Palfrey. 1995. “Quantal Response Equilibria for Normal Form Games." Games and Economic Behavior, 10(1): 6-38. 
Nagel, R. 1995. “Unraveling in Guessing Games: An Experimental Study.” American Economic Review, 85(5): 1313-1326.

Normann, H.T. 2011. “Vertical mergers, foreclosure and raising rival's cost-experimental evidence." The Journal of Industrial Economics, 59(3): 506-527.

Normann, H.-T., and R. Ricciuti. 2009. “Laboratory experiments for economic policy making." Journal of Economic Surveys, 23(3): 407-432.

Ordover, J., G. Saloner, and S Salop. 1990. "Equilibrium Vertical Foreclosure." American Economic Review, 80(1): 127-142.

Plott, C. R. 1982. “Industrial Organization Theory and Experimental Economics.” Journal of Economic Literature, 20(4): 1485-1527.

Plott, C. R. 1989. “An updated review of industrial organization: Applications of experimental methods." In Handbook of Industrial Organization. , ed. R. Schmalensee and R. Willig, Chapter 19, 1109-1176. North-Holland, Amsterdam.

Salinger, M. 1988. "Vertical Mergers and Market Foreclosures." Quarterly Journal of Economics, 103(2): 345-356.

Sloof, R., H. Oosterbeek, and J. Sonnemans. 2007. “Does making specific investments unobservable boost investment incentives?" Journal of Economics and Management Strategy, 16(4): 911-942.

Smith, V. L., G. L. Suchanek, and A. W. Williams. 1988. “Bubbles, Crashes, and Endogenous Expectations in Experimental Spot Asset Markets." Econometrica, 56(5): 1119-1151.

Stahl, D. O. 1993. "Evolution of Smart Players." Games and Economic Behavior, 5(4): 604617. 
Van Huyck, J. B., R. C. Battalio, and R. O. Beil. 1990. “Tacit Coordination Games, Strategic Uncertainty, and Coordination Failure." American Economic Review, 80(1): 234-248.

Williamson, O. 1975. Markets and Hierarchies: Some elementary considerations. New York: Free Press.

Williamson, O. 1985. The Economic Institutions of Capitalism. New York: Free Press.

Williams, R. 2012. “Using the Margins Command to Estimate and Interpret Adjusted Predictions and Marginal Effects." The Stata Journal, 12(2): 308-331. 


\section{Appendix}

\section{A IQ Questionnaire}

The following three questions were asked. Each good answer yields one point, while each wrong answer brings zero. The IQ score is the sum of the three.

1. A bat and a ball cost 1.10 in total. The bat costs $\$ 1.00$ more than the ball. How much does the ball cost? ... cents

2. If it takes 5 machines 5 minutes to make 5 widgets, how long would it take 100 machines to make 100 widgets? ... minutes

3. In a lake, there is a patch of lily pads. Every day, the patch doubles in size. If it takes 48 days for the patch to cover the entire lake, how long would it take for the patch to cover half of the lake? ... days

\section{B Pearson correlation tests}

Table 10: Pearson correlation coefficients

\begin{tabular}{lc}
\hline \hline Female and Employee & $0.382^{* * *}$ \\
Female and IQ & $-0.446^{* * *}$ \\
Employee and IQ & $-0.620^{* * *}$ \\
\hline Note: ${ }^{* * *}$ represents significance at $1 \%$ level.
\end{tabular}




\section{Figures of the evolution of the shares offered and ac- cepted}

Figure 2: Evolution of the shares offered by $U_{A}$ and $U_{B}$

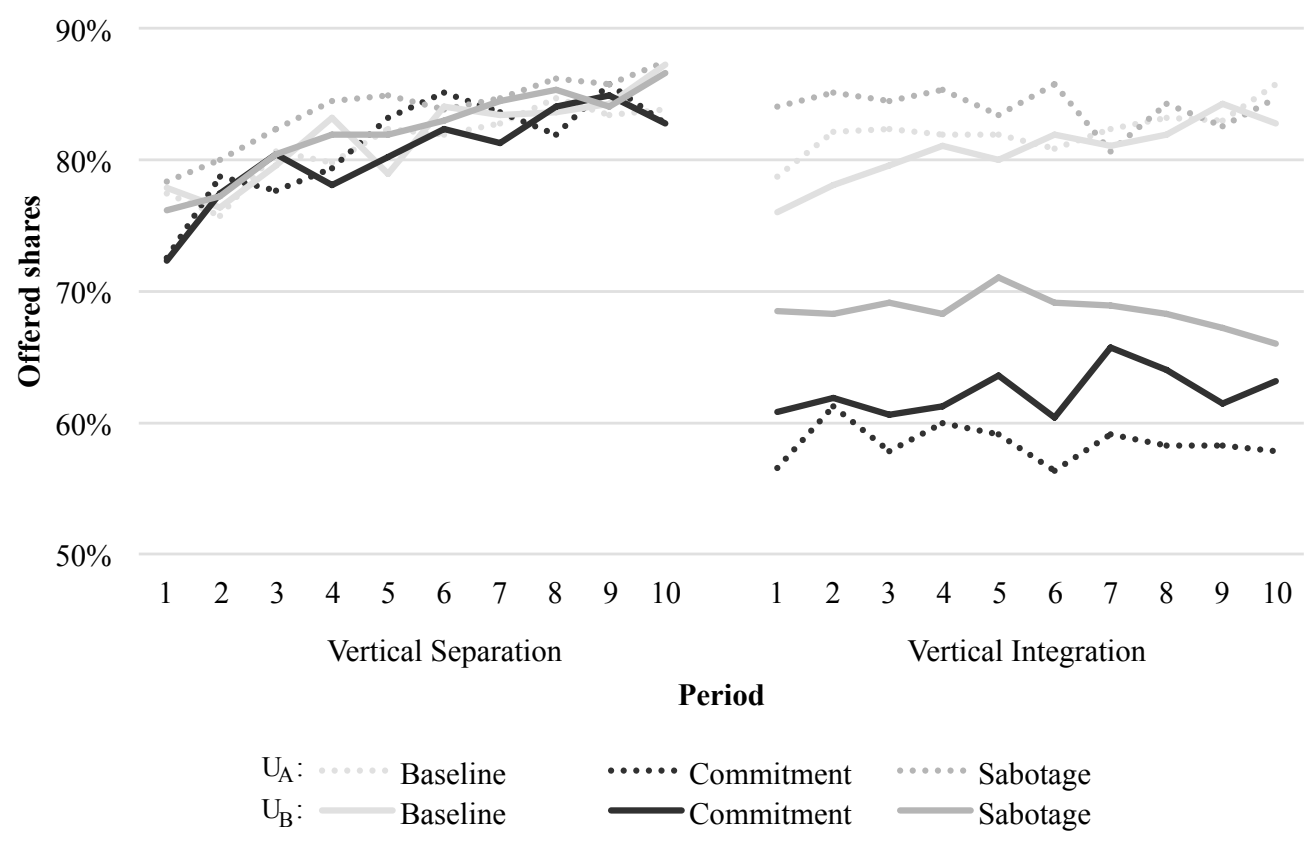

Figure 3: Evolution of the share accepted by $D$

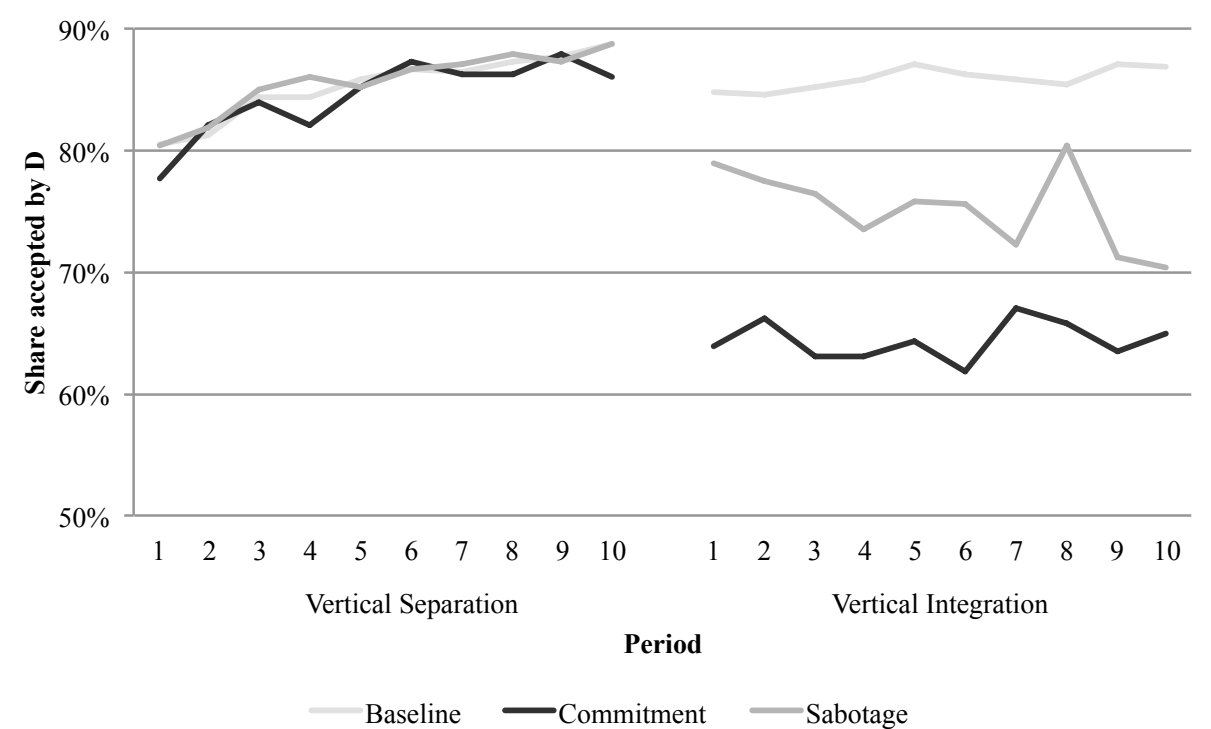




\section{Individual departures from theory}

We first define binary deviation scores for all individual subjects' decisions and present the average scores for all treatments and phases (section D.1).

\section{D.1 Deviation scores}

For each decision $d$ of each player $p$, we build a binary deviation score, $\sigma_{p}^{d}$, as follows. For binary decisions, the score is equal to 1 whenever the observed decision differs from the prediction, and to 0 otherwise. For continuous decisions, the score allows for a margin of error of up to 10 percentage points around the equilibrium level. ${ }^{34}$ More precisely:

$U_{A}$ subjects' hold-up decisions $\sigma_{A}^{H}$ is equal to 1 in the following instances:

- Commitment treatment: when $U_{A}$ opts for the commitment option under VS, or does not do so under VI;

- Sabotage treatment, if $U_{A}$ is selected ${ }^{35}$ when $U_{A}$ opts for the sabotage option under VS, or does not do so under VI.

$U_{B}$ subjects' offered shares $\sigma_{B}^{O}$ is equal to 1 in the following instances:

- Baseline treatment: when $U_{B}$ chooses a share in $[50 \%, 75 \%]$;

- Commitment treatment: when $U_{B}$ chooses a share in $[70 \%, 90 \%]$ if $U_{A}$ opted for the commitment option, or in $[50 \%, 75 \%]$ if $U_{A}$ did not do so;

- Sabotage treatment: when $U_{B}$ chooses a share in $[50 \%, 75 \%]$ under VS, or in $[70 \%, 90 \%]$ under VI.

$D$ subjects' investment decisions $\sigma_{D}^{I}$ is equal to 1 in the following instances:

- Baseline treatment: when $D$ does not invest;

- Commitment treatment: when $D$ invests if $U_{A}$ chose to commit himself, or fails to invest if $U_{A}$ chose instead not to commit himself;

- Sabotage treatment: when $D$ does not invest under VS, or invests under VI.

\footnotetext{
${ }^{34}$ This applies to the offered shares. However, the deviation score for the share offered by $U_{A}$ cannot be defined under VI in the Sabotage treatment (as any share can then be offered in equilibrium) or for subjects exerting the commitment option in the Commitment treatment. We therefore omit it here; we note however in Online Appendix B.2 that this score is not significantly affected by vertical integration.

${ }^{35} U_{A}$ is selected by $40 \%$ of $D$ subjects under VS and by $26 \%$ under VI.
} 
$D$ subjects' choice of supplier $\sigma_{D}^{U}$ is equal to 1 in the following instances:

- Sabotage treatment under VI: when $D$ chooses $U_{A}$ even though $U_{B}$ offered at least $55 \%$;

- otherwise: when $D$ chooses the supplier who offered the lower share.

Table 11 reports the average deviation score for each treatment and phase. All periods are taken into consideration. Accounting for potential learning effects (by ignoring the first two periods of each treatment/phase) does not qualitatively change the findings (see Table 16 in online Appendix B].

Table 11: Average deviation scores

\begin{tabular}{cccccc}
\hline \hline Treatment & Phase & $\sigma_{A}^{H}$ & $\sigma_{B}^{O}$ & $\sigma_{D}^{I}$ & $\sigma_{D}^{U}$ \\
\hline \multirow{2}{*}{ Baseline } & VS & & 0.24 & 0.18 & 0.06 \\
& VI & & 0.28 & 0.10 & 0.04 \\
\hline \multirow{2}{*}{ Commitment } & VS & 0.08 & 0.21 & 0.15 & 0.02 \\
& VI & 0.28 & 0.21 & 0.18 & 0.06 \\
\hline \multirow{2}{*}{ Sabotage } & VS & $0.10^{\mathrm{a}}$ & 0.19 & 0.08 & 0.10 \\
& VI & $0.22^{\mathrm{a}}$ & 0.51 & 0.52 & 0.24 \\
\hline Note: ${ }^{\text {a: } \text { For selected }} U_{A}$. & & & &
\end{tabular}

Under VS, we observe in Table 11 an average difference of $8 \%$ to $18 \%$ across treatments between the predicted investment behavior and the observed one. Under VI, this difference remains about the same $(10 \%)$ in the Baseline treatment, but increases substantially in the other two treatments (32\% for Commitment and 52\% for Sabotage)

\section{D.2 Effect of vertical integration on deviation scores}

Table 12 reports the marginal effect of vertical integration on the deviation scores in the Commitment and Sabotage treatments.

Table 12: Marginal effect of vertical integration on deviation scores

\begin{tabular}{lcccc}
\hline \hline & $\sigma_{A}^{H}$ & $\sigma_{B}^{O}$ & $\sigma_{D}^{I}$ & $\sigma_{D}^{U}$ \\
\hline Commitment & $0.198^{* * *}$ & 0.002 & 0.028 & $0.043^{*}$ \\
& $(0.074)$ & $(0.041)$ & $(0.036)$ & $(0.022)$ \\
Sabotage & 0.115 & $0.301^{* * *}$ & $0.389^{* * *}$ & $0.143^{* * *}$ \\
& $(0.078)$ & $(0.058)$ & $(0.044)$ & $(0.039)$ \\
\hline
\end{tabular}

Notes: Standard errors are reported in parentheses. ${ }^{* * *}$ represents significance at $1 \%$ level and ${ }^{*}$ at $10 \%$ level.

\footnotetext{
${ }^{36}$ See Online Appendix E.3 for a detailed analysis of the Baseline treatment. If anything, we observe slightly fewer departures in the VI phase, which may reflect a learning effect.
} 
Table 13 reports the marginal effect of $D$ subjects' departures from theory in their investment decisions on $U_{B}$ subjects' departures in the shares they offer, under VI in the two hold-up treatments. There is a positive impact in the Sabotage treatment (marginal effect of $17 \%$ ), where $D$ investing is positively correlated with $U_{B}$ subsequently offering too high shares in the same period. We did not find any other relevant interplay, in either phase, between deviations over sequential decisions (see Tables 19 and 20 in online Appendix B.3.

Table 13: Marginal effect of $\sigma_{D}^{I}$ on $\sigma_{B}^{O}$ under VI

\begin{tabular}{ccc}
\hline \hline & Commitment & Sabotage \\
\hline$\sigma_{D}^{I}$ on $\sigma_{B}^{O}$ & -0.014 & $0.175^{* * *}$ \\
& $(0.026)$ & $(0.059)$ \\
\hline
\end{tabular}

Notes: Standard errors are reported in parentheses. ${ }^{* * *}$ represents significance at $1 \%$ level.

\section{E Behavioral approaches}

\section{E.1 Level- $k$ thinking}

In what follows we present the main findings from applying level- $k$ thinking to the Sabotage and Commitment games. ${ }^{37}$ For simplicity we assume that, for $k \geq 1$, each level-k player believes that all the other players are of level- $(k-1)$. We also assume that when indifferent between several actions, players randomly choose each of these actions with equal probability. A more detailed analysis is provided in Online Appendix C.

\section{E.1.1 Sabotage}

Level-0 players play randomly. Hence, on level 0 of the Sabotage game, under both VS and VI: in stage $1, D$ invests with probability $1 / 2$; in stage 2 , both suppliers select each possible sharing-rule with probability $1 / 9$; in stage $3, D$ selects either supplier with probability $1 / 2$, regardless of the shares offered; and whenever selected, in stage $4 U_{A}$ uses the sabotage option with probability $1 / 2$.

From level 1 on, $U_{A}$ never uses the sabotage option under VS, and uses it whenever selected under VI.

On level 1, anticipating a random selection by a level-0 $D$, both suppliers offer the lowest share (50\%). In stage 3, D selects the offer providing the higher expected payoff,

\footnotetext{
${ }^{37}$ Another classic bounded rationality approach relies on the concept of quantal response equilibrium (see McKelvey and Palfrey (1995) and Normann 2011), which assumes that players do not choose the best response with probability one. Unfortunately, this approach is difficult to apply to multi-stage games such as the one studied here.
} 
given that she expects $U_{A}$ to engage in sabotage with probability $1 / 2.38$ In stage $1, D$ anticipates random offers by level-0 suppliers, and a random use of the sabotage option by $U_{A}$. Table 14 displays the probability distribution of the resulting best expected offer received by $D$.

Table 14: Level 1, probability distribution of the expected best offer

\begin{tabular}{|c|c|c|c|c|c|c|c|c|c|}
\hline Best offer & $51.25 \%$ & $53.75 \%$ & $55 \%$ & $56.25 \%$ & $58.75 \%$ & $60 \%$ & $61.25 \%$ & $63.75 \%$ & $65 \%$ \\
\hline Probability & $1 / 81$ & $1 / 81$ & $2 / 81$ & $2 / 81$ & $2 / 81$ & $4 / 81$ & $3 / 81$ & $3 / 81$ & $6 / 81$ \\
\hline Best offer & $66.25 \%$ & $68.75 \%$ & $70 \%$ & $71.25 \%$ & $75 \%$ & $80 \%$ & $85 \%$ & $90 \%$ & \\
\hline Probability & $4 / 81$ & $4 / 81$ & $8 / 81$ & $5 / 81$ & $9 / 81$ & $9 / 81$ & $9 / 81$ & $9 / 81$ & \\
\hline
\end{tabular}

As a result, $D$ expects a share of 72.55 and thus invests.

From level 2 on, $U_{A}$ is expected to use the sabotage option whenever selected under VI, and not to use it under VS. Hence, under VI, $U_{B}$ always offers $55 \%$ and $D$ never invests. By contrast, under VS, each supplier seeks to outbid his level-(k-1) rival; hence, suppliers' best offer increases gradually with $k$, reaches $70 \%$ (the share that leaves $D$ indifferent between investing or not) when $k=5$, and is maximal (90\%) from level 9 on.

\section{E.1.2 Commitment}

On level 0 of the commitment game, under both VS and VI: $U_{A}$ commits himself with probability $1 / 2$ in stage $0 ; D$ invests with probability $1 / 2$ in stage 1 ; in stage $2, U_{A}$ (if not committed) and $U_{B}$ select each of possible sharing-rule with probability $1 / 9$; in stage 3 , $D$ selects either supplier with probability $1 / 2$, regardless of the shares offered.

On level 1 , anticipating a random selection by $D, U_{B}$ offers the lowest share $(50 \%)$ whereas $U_{A}$ makes the commitment decision randomly and, if not committed, offers $50 \%$ as well. If $U_{A}$ does not commit himself in stage 0 , then $D$ anticipates random offers from $U_{A}$ and $U_{B}$. The probability distribution of the resulting best offer is presented in Table 15 and induces $D$ to invest (her expected payoff is then 21.4, higher than 18 when she does not invest). By contrast, if $U_{A}$ commits himself in stage 0 , then $D$ anticipates that the best offer will be determined by $U_{B}{ }^{\prime}$ s random selection. Her expected payoff is then $143 / 9$ whether she invests or not; $D$ thus invests randomly and, in stage 3 , selects the higher offer.

Table 15: Level 1, probability distribution of the best offer

\begin{tabular}{|c|c|c|c|c|c|c|c|c|c|}
\hline Best offer & $50 \%$ & $55 \%$ & $60 \%$ & $65 \%$ & $70 \%$ & $75 \%$ & $80 \%$ & $85 \%$ & $90 \%$ \\
\hline Probability & $\frac{1}{81}$ & $\frac{3}{81}$ & $\frac{5}{81}$ & $\frac{7}{81}$ & $\frac{9}{81}$ & $\frac{11}{81}$ & $\frac{13}{81}$ & $\frac{15}{81}$ & $\frac{17}{81}$ \\
\hline
\end{tabular}

On level 2, under both VS and VI, and regardless of $U_{A}$ 's commitment decision, $D$ expects $50 \%$ shares from level- 1 suppliers, and does not invest. Similarly, $U_{B}$ expects a

\footnotetext{
${ }^{38}$ Recall that $D$ 's payoff in case of sabotage is based on an effective share $\tilde{s} \equiv 52.5$ (see footnote 22); thus, if $U_{A}$ offers a share $s_{A}$, then selecting that offer gives $D$ an expected share $\left(s_{A}+\tilde{s}\right) / 2$.
} 
level-1 $U_{A}$ to offer $50 \%$ and thus offers the next best share $(55 \%)$ - offering $50 \%$ is less profitable, as it reduces by half the selection probability. Likewise, $U_{A}$ chooses to not commit himself, and offers a 55\% share - committing himself would furthermore reduce the probability of investment by a level-1 $D$.

From level 3 on, under both VS and VI, commitment by $U_{A}$ discourages investment by $D: U_{B}{ }^{\prime}$ s best response to level- $(k-1)$ players' strategies is then to offer a $55 \%$ share, and $D^{\prime}$ s is not to invest. However, an independent $U_{A}$ never commits himself: this would yield the lowest possible payoff (2), whereas not committing and matching $U_{B}$ 's offer, for example, would yield a higher payoff with positive probability. Furthermore, absent commitment, each supplier seeks to outbid his level-(k-1) rival; hence both suppliers' offers increase gradually with $k$, reach $70 \%$ (the share that leaves $D$ indifferent between investing or not) when $k=5$, and is maximal (90\%) from level 10 on. 39

It follows that $U_{A}$ never commits before $k=7$ (expecting no influence on investment, this would only limit his ability to compete) and $D$ never invests before before $k=6$, where it does so with probability $1 / 2$. Differences between VS and VI appear from level 7 on. Under VS, $U_{A}$ never commits himself, the suppliers compete and, anticipating high enough offers from level- $(k-1)$ suppliers, $D$ invests. Under VI, by contrast, $U_{A}$ commits himself to prevent $D$ from investing, as this strategy becomes more profitable than competing to supply $D$

\section{E.1.3 Insights}

Level- $k$ thinking predicts that vertical integration triggers substantial departures from theory in $U_{A}$ subjects' hold-up decisions in the Commitment treatment. This is because the hold-up decision comes first, and thus depends on $U_{A}$ 's anticipations regarding all subsequent decisions. On level 1, suppliers anticipate a random selection by a level- $0 D$ and thus offer the lowest share. It follows that, in the absence of commitment by $U_{A}$, the shares offered increase gradually, from $50 \%$ on level 1 to $90 \%$ from level 9 onward. Hence, $D$ does not invest until level 6 , where she invests with probability $1 / 2$. As a result, it is only from level 7 onward that $U_{A}$ commits himself to offering a low share, as predicted by theory.

By contrast, in the Sabotage treatment, the hold-up decision comes last, once all other decisions have been made and observed; it follows that, from level 1 onward, predictions coincide with theory: whenever selected by $D, U_{A}$ always uses the $S$ option under VI, and never uses it under VS.

\footnotetext{
${ }^{39}$ There is a slight difference in the progression of suppliers' shares in the two treatments, due to the role of $D^{\prime}$ s expectations about the hold-up decision. In the sabotage treatment, on level 2 the suppliers expect a level-1 $D$ to anticipate sabotage with probability $1 / 2$ from a level- $0 U_{A}$; by contrast, in the commitment treatment, uncertainty about the hold-up decision is resolved upfront, and even a level-1 $D$ thus observes that $U_{A}$ does not exert hold-up.

${ }^{40}$ For example, by committing himself on level-7 under VI, $U_{A}$ prevents $D$ from investing and obtains a payoff of 54; he expects that not committing himself (and offering a 80\% share) would instead induce the level-6 $D$ to invest with probability $1 / 2$, giving him an expected payoff of 51 .
} 
Level- $k$ thinking cannot explain either the observed impact of vertical integration on $D$ and $U_{B}$ subjects' departures from theory. $D^{\prime}$ 's investment decisions are the same in the two treatments: under VS, $D$ invests from level 7 onward; under VI, $D$ never invests from level 2 onward in the Sabotage treatment and in case of commitment in the other treatment. Concerning $U_{B}$ 's behavior, level- $k$ thinking actually predicts more departures from theory in the Commitment treatment than in the Sabotage treatment, which goes in the opposite direction, compared with the observed behavior. The reason hinges again on the role of anticipations. From level 2 onward, sabotage is not a concern under VS but is expected under VI. Thus, under VI, $U_{B}$ 's offer is primarily driven by $D^{\prime}$ s fear of sabotage, and coincides with theory from then on. ${ }^{41}$ Under VS, the offer of a level- $k$ supplier is instead driven by his expectations about a level- $(k-1)$ rival's offer. As noted above, level-1 suppliers expect a random selection and thus offer the lowest share; these offers are then enhanced only gradually, and do not coincide with theory before level 9. Vertical integration thus reduces $U_{B}$ 's departures from theory rather than exacerbating them.

\section{E.2 Social preferences}

Social preferences can explain why a fraction of $U_{A}$ subjects are reluctant - in both treatments - to exert the hold-up option under VI (see Table 11). Beliefs about such preferences may, in turn, affect the behavior of $D$ and $U_{B}$ subjects in the Sabotage treatment, where $U_{A}$ 's hold-up decision comes last. By contrast, these beliefs cannot play any role in the Commitment treatment, where any uncertainty about $U_{A}$ 's hold-up behavior is resolved upfront.

We now show that beliefs about $U_{A}$ 's social preferences can actually explain not only $D$ and $U_{B}$ subjects' observed departures in the Sabotage treatment, but also their correlation. The intuition is that what matters for $U_{B}$ is $D^{\prime}$ s beliefs about $U_{A}$ 's social preferences, rather than $U_{A}$ 's actual preferences or $U_{B}$ 's own beliefs about them. It follows that $D$ investing signals that she is optimistic about $U_{A}$ 's behavior, which in turn induces $U_{B}$ to be more generous in order to be selected.

\section{E.2.1 Formal analysis}

To see this, we introduce the possibility of social preferences in a stylized version of the Sabotage treatment under vertical integration, where: (i) $U_{A}$ is replaced by an automatized robot, which may either provide a good option reflecting social preferences, or an unattractive one; (ii) $U_{B}$ can choose among two offers; and (iii) $D$ is either optimistic or pessimistic about $U_{A}$ 's behavior.

- Players. There are two players: $U_{B}$ and $D$. In addition, $D$ has access to an outside option (standing for $\left.U_{A}\right)$, the quality of which is "good" $(q=G)$ with probability $x$ and "bad"

\footnotetext{
${ }^{41}$ Specifically, on level- $2 U_{B}$ believes that a level- $1 D$ expects a level- $0 U_{A}$ to sabotage with probability $1 / 2$; from level-3 on, $U_{B}$ believes that a level- $(k-1) D$ expects a level- $(k-2) U_{A}$ to sabotage with probability 1. In both instances, $U_{B}$ believes that offering $55 \%$ suffices to win.
} 
$(q=B)$ otherwise; a good outside option enables $D$ to obtain a share $\hat{s} \in(0,1)$ of the revenue that she generates, whereas a bad outside option leaves her no revenue.

- Information. At the beginning of the game, $U_{B}$ and $D$ believe that the outside option is good with probability $\hat{x}$. $D$ then observes a binary signal $\sigma \in\{g, b\}$, distributed in such a way that 42

- with probability $\lambda \in(0,1), D$ observes $\sigma=g$; she then becomes "optimistic "and believes that the outside option is good with probability $x_{H} \in(0,1)$;

- with probability $1-\lambda, D$ observes $\sigma=b$; she then becomes "pessimistic" and believes that the outside option is good with lower probability $x_{L} \in\left(0, x_{H}\right)$.

- Decisions. $D$ chooses whether or not to invest (at cost $I>0$ ); she generates a revenue $R>0$ if she does not invest and $R+\Delta>R$ if she invests. $U_{B}$ chooses whether to offer $D$ a share $s_{H} \in(0,1)$ or a lower share $s_{L} \in\left(0, s_{H}\right)$.

- Payoffs. Let $\delta \in\{0,1\}$ denote $D^{\prime}$ s investment decision (where $\delta=1$ if $D$ invests, and $\delta=0$ otherwise), and $s \in\left\{s_{L}, s_{H}\right\}$ denote the share offered by $U_{B}$. The payoffs are as follows:

- If $D$ opts for the outside option, then $D$ obtains $\hat{s}(R+\delta \Delta)-\delta I$ if the outside option is of good quality and $-\delta I$ otherwise; $U_{B}$ obtains 0 .

- If instead $D$ accepts $U_{B}$ 's offered share $s$, then $D$ obtains $s(R+\delta \Delta)-\delta I$ and $U_{B}$ obtains $(1-s)(R+\delta \Delta)$.

- Timing. There are three stages:

- Stage 0: Nature randomly draws the quality $q \in\{G, B\}$ of the outside option and the signal $\sigma \in\{g, b\}$; the former is not observed, whereas the latter is privately observed by $D$.

- Stage 1: $D$ chooses whether or not to invest; this decision is observed by $U_{B}$.

- Stage 2: $U_{B}$ chooses whether to offer $s_{L}$ or $s_{H}$; having observed the offer, $D$ chooses whether to accept it, or to select the outside option.

We assume that the ratio $I / \Delta$ and the shares satisfy:

$$
s_{H}>x_{H} \hat{s}>\frac{I}{\Delta}>s_{L}>x_{L} \hat{s} .
$$

That is, investing is profitable for $D$ only if she obtains $s_{H}$ from $U_{B}$, or if she is optimistic and picks the outside option; in addition, $U_{B}$ can win $D^{\prime}$ s business with $s_{L}$ when she is pessimistic, otherwise he needs instead to offer her the higher share $s_{H}$.

\footnotetext{
${ }^{42}$ That is, the joint distribution of $q$ and $\sigma$ is given by $\operatorname{Pr}(G, g)=\lambda x_{H}, \operatorname{Pr}(B, g)=\lambda\left(1-x_{H}\right), \operatorname{Pr}(G, b)=$ $(1-\lambda) x_{L}$ and $\operatorname{Pr}(B, b)=(1-\lambda)\left(1-x_{L}\right)$.
} 
We moreover assume that $D$ is likely to be pessimistic:

$$
\lambda<\bar{\lambda} \equiv \frac{s_{H}-s_{L}}{1-s_{L}} .
$$

This rules out a trivial outcome in which $U_{B}$ always offers $s_{H}$ and $D$ always invests.

Under these assumptions, $D^{\prime}$ s investment decision indeed signals her belief, which in turn affects $U_{B}$ 's decision:

Proposition 1 Under Assumptions (1) and (2), there exists a unique equilibrium, in which:

- D invests with probability 1 when optimistic, and with probability

$$
y^{*} \equiv \frac{\lambda\left(1-s_{H}\right)}{(1-\lambda)\left(s_{H}-s_{L}\right)} \in(0,1)
$$

otherwise.

- $U_{B}$ offers $s_{L}$ with probability 1 when $D$ does not invest, and offers $s_{H}$ with probability

$$
z^{*} \equiv \frac{I-s_{L} \Delta}{\left(s_{H}-s_{L}\right)(R+\Delta)} \in(0,1)
$$

otherwise.

Proof. See Online Appendix D.

\section{E.2.2 Insights}

The above analysis confirms that introducing the possibility of $U_{A}$ being reluctant to exert hold-up induces $D$ and $U_{B}$ to depart from the initially predicted behavior, in such a way that $D^{\prime}$ s investment decision moreover influences $U_{B}$ 's behavior: in equilibrium, $D$ invests with positive probability, in which case $U_{B}$ responds by offering the higher share $s_{H}$ with positive probability. This is because $D$ is more likely to invest when she is optimistic about $U_{A}$ 's behavior; hence, when she does invest, $U_{B}$ expects $D$ to be more likely to be optimistic, which induces him to be more generous. By contrast, when $D$ does not invest, she reveals that she is pessimistic and $U_{B}$ therefore expects her to accept the lower share.

It can moreover be noted that introducing uncertain social preferences for $U_{A}$ has no impact under vertical separation, as $U_{A}$ never engages in sabotage anyway. Likewise, in the Commitment treatment, introducing such a possibility would have no impact under both vertical separation and vertical integration, as the associated uncertainty would be resolved before the other players have to make decisions. 


\section{Online appendix for \\ Vertical Integration as a Source of Hold-up: an Experiment Not for publication}

\section{A Instructions}

\section{A.1 Instructions for the Baseline treatment}

We present below the English translation of the instructions handed out and read to the subjects participating in the Baseline treatment.

\section{Instructions Baseline (English translation)}

You are about to participate to an experiment on decision-making. This experiment is realized jointly by the Econometrics Laboratory at Ecole Polytechnique, Toulouse School of Economics, and the INRA-ALISS Laboratory. During this session, you will be able to earn money. How much you will earn will depend on your decisions and also on the decisions taken by other participants with whom you will be interacting. In addition to this amount you will also receive a participation fee of 5 Euros. Your earnings will be paid cash at the end of the experiment, in a separate room for confidentiality reasons.

During the experiment, you have been randomly assigned to two separate rooms. Because there are many of you, in total 30 participants, we had to allocate you into two rooms. This allocation is purely random and has no relation to the decisions you have to make during the experiment. During the experiment you will have to interact with other participants in the same room as well as participants in the other room.

These instructions explain in detail what are the decision-making tasks you will have to make during the experiment, and how your payment is going to be computed. All the participants receive the same instructions, irrespective of the room they are allocated to.

The decisions you make during the experiment are anonymous.

If you have questions about the instructions, please raise your hand. We will answer your questions privately. Along the session, it is prohibited to communicate with each other, subject to being excluded from the session and not receiving any payment. We also require that you do not use your mobile phones. 


\section{Proceedings of the experiment}

At the beginning of this experiment, you will be attributed a role that you will keep throughout the experiment. The computer program assigns these roles randomly. 10 participants will be assigned the role $A, 10$ the role $B$ and 10 the role $C$. You will participate to two phases of 10 periods each. You will keep the same role for all the periods of the experiment. You will thus keep the same role for these two phases.

We present first the proceedings of the first phase. Once the first phase will be over, we will give you the instructions for the second phase. The two phases are independent from each other. At the end of the experiment, one period among the twenty periods will be randomly drawn by the computer; this will determine your payments for the experiment.

\section{phase VS}

This phase consists in ten periods. All your decisions are anonymous. We describe below the proceedings of phase1.

Description of each period At the beginning of each period, groups of three players are composed with one player A, one B and one C. These three players will interact throughout the period. The interactions of these three players create revenues. All the groups are anonymous: you will not know with whom you are playing.

During the ten periods of phase VS, players A and B interact only once: it is not possible that players A and B interact once more in phase VS. Players C are randomly affected to a player $A$ and a player B: it is possible that a player $C$ interacts several times with a player A or a player B but it is not automatic.

Inside each group of three participants, each period is composed of three stages:

- In stage 1, player $C$ makes a first decision. He must choose between two options:

- "Invest" or

- "Not invest".

- In stage 2 , the choice of player $\mathrm{C}$ in stage 1 is revealed to players $\mathrm{A}$ and $\mathrm{B}$. Players $\mathrm{A}$ and B make their decisions, simultaneously and without consulting each other. Each of them must choose one among the following nine options, which correspond to a percentage of the total revenues they plan to leave to player $\mathrm{C}$ :

- $50 \%$ or

- $55 \%$ or

- $60 \%$ or

- $65 \%$ or

- $70 \%$ or

- $75 \%$ or

- $80 \%$ or 
$-85 \%$ or

$-90 \%$.

- In stage 3, the choices of players A and B in stage 2 are revealed to player C. Player $\mathrm{C}$ makes a second decision. He must choose one of the two players A and B :

- "Player A" or

- "Player B" .

How are the gains of each player computed in each period?

The gains of players A, B and C at each period depend on the choices of all of them. All the amounts reported in the following tables are in euros.

Gains of player C The gains of player C depend on his investment decision and on the percentage of the revenues that will be left to him subsequently. This percentage of the revenues corresponds to the percentage of the revenues offered by the player $\mathrm{A}$ or $\mathrm{B}$ selected by player $C$ in stage 3 . The gains of player $C$ in each situation are displayed in the following table:

Gains of C

\begin{tabular}{lcccccccccc}
\hline \hline Percentage of revenues left to C & $50 \%$ & $55 \%$ & $60 \%$ & $65 \%$ & $70 \%$ & $75 \%$ & $80 \%$ & $85 \%$ & $90 \%$ \\
\hline \multirow{2}{*}{ Choice of C } & Not invest & 10 & 12 & 13 & 14 & 16 & 17 & 19 & 20 & 22 \\
& Invest & 1 & 5 & 8 & 12 & 16 & 20 & 23 & 27 & 31 \\
\hline
\end{tabular}

Example: suppose that

- In stage 1, player $C$ chooses to not invest;

- In stage 2, player A chooses to leave $85 \%$ of the revenues to player C; Player B chooses to leave $55 \%$ of the revenues to player $C$;

- In stage 3, player $C$ selects player $A$.

The gain of player $C$ for this period is $20 €$.

Gains of players A and B The gains of players A and B depend on the percentage of the revenues that they offer to leave to player $C$ and on the choices of player $C$ (to invest or not, and player A or B).

- If player $\mathrm{C}$ chooses the offer of player $\mathrm{A}$ in stage 3:

- The gains of player A in each situation are displayed in the following table;

- The gain of player $B$ is $2 €$.

- If player C chooses the offer of player B in stage 3:

- The gains of player B in each situation are displayed in the following table; 
Gains of A or B

\begin{tabular}{lcccccccccc}
\hline \hline Percentage of revenues left to C & $50 \%$ & $55 \%$ & $60 \%$ & $65 \%$ & $70 \%$ & $75 \%$ & $80 \%$ & $85 \%$ & $90 \%$ \\
\hline \multirow{2}{*}{ Choice of C } & Not invest & 63 & 57 & 50 & 44 & 38 & 32 & 25 & 19 & 13 \\
& Invest & 74 & 67 & 59 & 52 & 44 & 37 & 30 & 22 & 15 \\
\hline
\end{tabular}

- The gain of player $A$ is $2 €$.

Example. Suppose that:

- In stage 1, player $C$ chooses to not invest;

- In stage 2, player A chooses to leave $85 \%$ of the revenues to player C; Player B chooses to leave $55 \%$ of the revenues to player $C$;

- In stage 3, player $C$ selects player $A$.

The gain of player $A$ for this period is $19 €$. The gain of player $B$ for this period is $2 €$.

Information received by the players at the end of each period At the end of each period, the screen displays the amount of the player's gain for this period. Each player learns only his gain for the current period; the gains of the other players are not displayed.

The screen also displays the decisions taken by all players during the period: the three players in each group are reminded of the choices of player $C$ in stage 1 and in stage 3 and the choices of players A and B in stage 2 .

Please read these instructions carefully. Before starting phase VS of this experiment, you will answer a few questions about these instructions. As soon as you will have correctly answered these questions, we will be able to start.

Thanks for your participation 


\section{Questions about the instructions}

Please answer the following questions about the instructions

- At the beginning of each period, groups of three participants consisting of one player A, one player B and one player C are constituted.

TRUE $\square \quad$ FALSE $\square$

- A player A and a player B can be part of the same group several times during a given phase.

\section{TRUE $\square$ FALSE}

- A player A and a player C can be part of the same group several times during a given phase.

\section{TRUE $\square \quad$ FALSE}

- A phase consists of 10 periods. TRUE $\square \quad$ FALSE

- At the end of the experiment, one period among the 20 periods played is randomly drawn. Each participant will receive as a payment for the experiment the amount of his gains for this period, plus the participation fee of $5 €$.

\section{TRUE $\square \quad$ FALSE $\square$}

- At each period, the three players of one group learn their own gains and the gains of the two other players of their group.

\section{TRUE $\square \quad$ FALSE $\square$}

Example 1. Suppose that:

- In stage 1, player $C$ chooses to not invest;

- In stage 2, player A chooses to leave $50 \%$ of the revenues to player C; player B chooses to leave $90 \%$ of the revenues to player $C$;

- In stage 3, player $C$ selects player B.

What is the gain of player $A$ ?

What is the gain of player $B$ ?

What is the gain of player $C$ ?

Example 2. Suppose that:

- In stage 1, player $C$ chooses to invest;

- In stage 2, player A chooses to leave $70 \%$ of the revenues to player $C$; player B chooses to leave $80 \%$ of the revenues to player $C$;

- In stage 3, player $C$ chooses player $A$.

What is the gain of player $A$ ?

What is the gain of player $B$ ?

What is the gain of player $C$ ? 


\section{phase VI}

The instructions for phase VI are identical to the instructions for phase VS, except for the computation of the gains of players A and B. For the record, these instructions detail the proceedings of each period. As only the computation of the gains of players $\mathrm{A}$ and $\mathrm{B}$ differs from that in phase VS, we will read this part only together. It corresponds to the text written in blue.

You keep the same role than in phase VS of the experiment. All your decisions are anonymous.

This phase is independent from phase VS. This phase consists in ten periods. We describe below the proceedings of phase VI.

Description of each period As in phase VS, at the beginning of each period, groups of three players are composed with one player A, one B and one C. These three players will interact throughout the period. The interactions of these three players create revenues. All the groups are anonymous: you will not know with whom you are playing.

During the ten periods of phase VI, players A and B interact only once: it is not possible that players A and B interact once more in phase VI. Players C are randomly affected to a player A and a player B: it is possible that a player $C$ interacts several times with a player A or a player B but it is not automatic.

As in phase VS, inside each group of three participants, each period consists in three stages:

- In stage 1, player $C$ makes a first decision. He must choose between two options:

- "Invest" or

- "Not invest".

- In stage 2, the choice of player C in stage 1 is revealed to players A and B. Players A and B make their decisions, simultaneously and without consulting each other. Each of them must choose one among the following nine options, which correspond to a percentage of the total revenues they plan to leave to player $C$ :

$-50 \%$ or

- $55 \%$ or

- $60 \%$ or

- $65 \%$ or

- $70 \%$ or

- $75 \%$ or

- $80 \%$ or

- $85 \%$ or

- $90 \%$. 
- In stage 3, the choices of players A and B in stage 2 are revealed to player C. Player $\mathrm{C}$ makes a second decision. He must choose one of the two players A and B :

- "Player A " or

- "Player B" .

How are the gains of each player computed in each period?

The gains of players A, B and C at each period depend on the choices of each of them. All the amounts reported in the following tables are in Euros.

\section{Gains of player C}

- The gain of player C is computed as in phase VS.

- The gain of player $\mathrm{C}$ depends on his investment decision and on the percentage of the revenues that will be left to him subsequently.

- This percentage of the revenues corresponds to the percentage of the revenues offered by the player A or B selected by player C in stage 3 .

The gain of player $\mathrm{C}$ in each situation is displayed in the following table (this table is the same than in phase VS):

Gains of $C$

\begin{tabular}{lcccccccccc}
\hline \hline Percentage of revenues left to C & $50 \%$ & $55 \%$ & $60 \%$ & $65 \%$ & $70 \%$ & $75 \%$ & $80 \%$ & $85 \%$ & $90 \%$ \\
\hline \multirow{2}{*}{ Choice of C } & Not invest & 10 & 12 & 13 & 14 & 16 & 17 & 19 & 20 & 22 \\
& Invest & 1 & 5 & 8 & 12 & 16 & 20 & 23 & 27 & 31 \\
\hline
\end{tabular}

Gains of players A and B The gains of players A and B are computed differently in phase VI compared to phase VS. The gains of players A and B depend from the percentage of the revenues that they offer to leave to player $C$ and from the choices of player $C$ (to invest or not, and player A or B).

- If player $\mathrm{C}$ chooses the offer of player $\mathrm{A}$ in stage 3:

- The gains of player A in each situation are displayed in the following table (this table is not the same than in phase VS);

- The gain of player B is $2 €$.

- If player C chooses the offer of player B in stage 3:

- The gains of player B in each situation are displayed in the following table (this table is not the same than in phase VS);

- The gain of player $A$ is $2 €$. 
Gains of A and B

\begin{tabular}{lcccccccccc}
\hline \hline Percentage of revenues left to C & $50 \%$ & $55 \%$ & $60 \%$ & $65 \%$ & $70 \%$ & $75 \%$ & $80 \%$ & $85 \%$ & $90 \%$ \\
\hline \multirow{2}{*}{ Choice of C } & Not invest & 15 & 13 & 12 & 10 & 9 & 7 & 6 & 4 & 3 \\
& Invest & 37 & 33 & 30 & 26 & 22 & 19 & 15 & 11 & 7 \\
\hline
\end{tabular}

$\mathrm{ht}]$

\begin{tabular}{lll}
\multicolumn{3}{c}{ Additional payoff for A } \\
\hline \hline & Guaranteed amount \\
\hline \multirow{2}{*}{ Choice of C } & Not invest & 52 \\
& Invest & 29 \\
\hline
\end{tabular}

In addition to the amount displayed above, player $\mathrm{A}$ also receives a guaranteed amount that depends on the investment choice made by $\mathrm{C}$. Whether player $\mathrm{C}$ selects $\mathrm{A}$ or $\mathrm{B}$ in stage 3, player A is certain to receive this guaranteed amount. This guaranteed amount is displayed in the following Table:

Example. Suppose that:

- In stage 1, player $C$ chooses to not invest;

- In stage 2, player A chooses to leave $85 \%$ of the revenues to player C; player B chooses to leave $55 \%$ of the revenues to player $C$;

- In stage 3, player $C$ selects player $A$.

The gain of player $A$ for this period is $4 €+52 €=56 €$. The gain of player $B$ for this period is $2 €$.

Information received by the players at the end of each period As in phase VS, at the end of each period, the screen displays the amount of the player's gain for this period. Each player learns only his gain for the current period; the gains of the other players are not displayed.

The screen also displays the decisions taken by all players during the period: the three players in each group are reminded of the choices of player $C$ in stage 1 and in stage 3 and the choices of players A and B in stage 2.

Please read these instructions carefully. Before starting phase VI of this experiment, you will answer a few questions about these instructions. As soon as you will have correctly answered these questions, we will be able to start. 


\section{Questions about the instructions}

Please answer the following questions about the instructions

- The table of the gains of player A, apart from the guaranteed amount, is the same as in phase VS.

\section{TRUE $\square \quad$ FALSE}

- The table of the gains of player B is the same as in phase VS.

\section{TRUE $\square \quad$ FALSE}

- The table of the gains of player C is the same as in phase VS.

TRUE $\square \quad$ FALSE $\square$

- The guaranteed amount is received by player A and player B.

TRUE $\square \quad$ FALSE

- Player A receives a guaranteed amount only if he is chosen by C in stage 3.

TRUE $\square \quad$ FALSE

- The guaranteed amount received by player A depends on the investment choice by player $C$ in stage 1 .

\section{TRUE $\square$ FALSE}

Example 1. suppose that:

- In stage 1, player $C$ chooses to not invest;

- In stage 2, player A chooses to leave $50 \%$ of the revenues to player C; player B chooses to leave $90 \%$ of the revenues to player $C$;

- In stage 3, player $C$ selects player $B$.

What is the gain of player $A$ ?

What is the gain of player $B$ ?

What is the gain of player $C$ ?

Example 2. Suppose that:

- In stage 1, player $C$ chooses to invest;

- In stage 2, player A chooses to leave $70 \%$ of the revenues to player C; player B chooses to leave $80 \%$ of the revenues to player $C$;

- In stage 3, player $C$ chooses player $A$.

What is the gain of player $A$ ?

What is the gain of player $B$ ?

What is the gain of player $C$ ? 


\section{A.2 Instructions for the Commitment treatment}

We present below the English translation of the instructions handed out and read to the subjects participating in the Commitment treatment.

\section{Instructions Commitment (English translation)}

You are about to participate to an experiment on decision-making. This experiment is realized jointly by the Econometrics Laboratory at Ecole Polytechnique, Toulouse School of Economics, and the INRA-ALISS Laboratory. During this session, you will be able to earn money. How much you will earn will depend on your decisions and also on the decisions taken by other participants with whom you will be interacting. In addition to this amount you will also receive a participation fee of 5 Euros. Your earnings will be paid cash at the end of the experiment, in a separate room for confidentiality reasons.

During the experiment, you have been randomly assigned to two separate rooms. Because there are many of you, in total 30 participants, we had to allocate you into two rooms. This allocation is purely random and has no relation to the decisions you have to make during the experiment. During the experiment you will have to interact with other participants in the same room as well as participants in the other room.

These instructions explain in detail what are the decision-making tasks you will have to make during the experiment, and how your payment is going to be computed. All the participants receive the same instructions, irrespective of the room they are allocated to.

The decisions you make during the experiment are anonymous.

If you have questions about the instructions, please raise your hand. We will answer your questions privately. Along the session, it is prohibited to communicate with each other, subject to being excluded from the session and not receiving any payment. We also require that you do not use your mobile phones. 


\section{Proceedings of the experiment}

At the beginning of this experiment, you will be attributed a role that you will keep throughout the experiment. The computer program assigns these roles randomly. 10 participants will be assigned the role $A, 10$ the role $B$ and 10 the role $C$. You will participate to two phases of 10 periods each. You will keep the same role for all the periods of the experiment. You will thus keep the same role for these two phases.

We present first the proceedings of the first phase. Once the first phase will be over, we will give you the instructions for the second phase. The two phases are independent from each other. At the end of the experiment, one period among the twenty periods will be randomly drawn by the computer; this will determine your payments for the experiment.

\section{phase VS}

This phase consists in ten periods. All your decisions are anonymous. We describe below the proceedings of phase1.

Description of each period At the beginning of each period, groups of three players are composed with one player A, one B and one C. These three players will interact throughout the period. The interactions of these three players create revenues. All the groups are anonymous: you will not know with whom you are playing.

During the ten periods of phase VS, players A and B interact only once: it is not possible that players A and B interact once more in phase VS. Players C are randomly affected to a player $A$ and a player $B$ : it is possible that a player $C$ interacts several times with a player A or a player B but it is not automatic.

Inside each group of three participants, each period is composed of four stages:

- In stage 1, player A makes a decision. He chooses either to commit himself or to not commit himself to leaving a 50\% revenue share to player $\mathrm{C}$. He must choose among the following two options:

- "I commit myself to leaving a 50\% revenue share" or

- "I do not commit myself".

If player A chooses to commit himself, he has no decision to make in stage 3 . If he chooses to not commit himself, he has a decision to make in stage 3 .

- In stage 2 , the choice of player A made in stage 1 is revealed to player C. Player C makes a first decision. He must choose between two options:

- "Invest" or

- "Not invest". 
- In stage 3 , the choices of player $A$ in stage 1 and of player $C$ in stage 2 are revealed to players A and B. Player A makes his decision if he chose not to commit himself in stage 1 (and has no decision to make otherwise). Player B makes his decision. When player A and B make a decision, they make it simultaneously and without consulting each other. Each of them must choose one among the following nine options, which correspond to a percentage of the total revenues they plan to leave to player $C$ :

- $50 \%$ or

- $55 \%$ or

- $60 \%$ or

- $65 \%$ or

- $70 \%$ or

- $75 \%$ or

- $80 \%$ or

$-85 \%$ or

$-90 \%$.

- In stage 4 , the choices of players $\mathrm{A}$ and B in stage 2 are revealed to player C. Player $\mathrm{C}$ makes his decision. He must choose one of the two players $\mathrm{A}$ and $\mathrm{B}$ :

- "Player A " or

- "Player B" .

How are the gains of each player computed in each period?

The gains of players A, B and C at each period depend on the choices of all of them. All the amounts reported in the following tables are in euros.

Gains of player C The gains of player C depend on his investment decision and on the percentage of the revenues that will be left to him subsequently. This percentage of the revenues corresponds to the percentage of the revenues offered by the player A or $B$ selected by player $C$ in stage 4 . The gains of player $C$ in each situation are displayed in the following table:

Gains of C

\begin{tabular}{lcccccccccc}
\hline \hline Percentage of revenues left to C & $50 \%$ & $55 \%$ & $60 \%$ & $65 \%$ & $70 \%$ & $75 \%$ & $80 \%$ & $85 \%$ & $90 \%$ \\
\hline \multirow{2}{*}{ Choice of C } & Not invest & 10 & 12 & 13 & 14 & 16 & 17 & 19 & 20 & 22 \\
& Invest & 1 & 5 & 8 & 12 & 16 & 20 & 23 & 27 & 31 \\
\hline
\end{tabular}

Example: suppose that

- In stage 1, player A chooses to not not commit himself to leaving 50\% of revenues to player C ;

- In stage 2, player $C$ chooses to not invest;

- In stage 3, player A chooses to leave $85 \%$ of the revenues to player C; Player B chooses to leave $55 \%$ of the revenues to player $C$; 
- In stage 4, player $C$ selects player $A$.

The gain of player $C$ for this period is $20 €$.

Gains of players A and B The gains of players A and B depend on the percentage of the revenues that they offer to leave to player $C$ and on the choices of player $C$ (to invest or not, and player A or B).

- If player $\mathrm{C}$ chooses the offer of player $\mathrm{A}$ in stage 4 :

- The gains of player A in each situation are displayed in the following table;

- The gain of player $\mathrm{B}$ is $2 €$.

- If player $C$ chooses the offer of player B in stage 4 :

- The gains of player B in each situation are displayed in the following table;

- The gain of player $A$ is $2 €$.

Gains of A or B

\begin{tabular}{lcccccccccc}
\hline \hline Percentage of revenues left to C & $50 \%$ & $55 \%$ & $60 \%$ & $65 \%$ & $70 \%$ & $75 \%$ & $80 \%$ & $85 \%$ & $90 \%$ \\
\hline \multirow{2}{*}{ Choice of C } & Not invest & 63 & 57 & 50 & 44 & 38 & 32 & 25 & 19 & 13 \\
& Invest & 74 & 67 & 59 & 52 & 44 & 37 & 30 & 22 & 15 \\
\hline
\end{tabular}

Example. Suppose that:

- In stage 1, player A do not commit himself to leaving a 50\% share of revenues to Player C ;

- In stage 2, player $C$ chooses to not invest;

- In stage 3, player A chooses to leave $85 \%$ of the revenues to player C; Player B chooses to leave $55 \%$ of the revenues to player $C$;

- In stage 4 , player $C$ selects player $A$.

The gain of player $A$ for this period is $19 €$. The gain of player $B$ for this period is $2 €$.

Information received by the players at the end of each period At the end of each period, the screen displays the amount of the player's gain for this period. Each player learns only his gain for the current period; the gains of the other players are not displayed.

The screen also displays the decisions taken by all players during the period: the three players in each group are reminded of the choices of player $C$ in stage 2 and in stage 4 , the choice of player A in stage 1 and in stage 3 and the choice of player B in stage 3 . 
Please read these instructions carefully. Before starting phase VS of this experiment, you will answer a few questions about these instructions. As soon as you will have correctly answered these questions, we will be able to start.

Thanks for your participation! 


\section{Questions about the instructions}

Please answer the following questions about the instructions

- At the beginning of each period, groups of three participants consisting of one player A, one player B and one player C are constituted. TRUE $\square$ FALSE $\square$

- A player A and a player B can be part of the same group several times during a given phase.

\section{TRUE $\square \quad$ FALSE}

- A player A and a player C can be part of the same group several times during a given phase.

\section{TRUE $\square \quad$ FALSE}

- A phase consists of 10 periods.

\section{TRUE $\square \quad$ FALSE}

- At the end of the experiment, one period among the 20 periods played is randomly drawn. Each participant will receive as a payment for the experiment the amount of his gains for this period, plus the participation fee of $5 €$.

TRUE $\square \quad$ FALSE $\square$

- At each period, the three players of one group learn their own gains and the gains of the two other players of their group.

TRUE $\square \quad$ FALSE $\square$

- If player A chose to commit himself to leaving player C a $50 \%$ revenue share in stage 1 , he may change this decision in stage 3.

\section{TRUE $\square \quad$ FALSE}

\section{Example 1. Suppose that:}

- In stage 1, player A chooses to commit himself to leaving a 50\% share of revenues to player C.

- In stage 2, player $C$ chooses to not invest;

- In stage 3, player A has no decision to make because he committed himself in stage 1 to leaving a $50 \%$ share of revenues to player C; player B chooses to leave $90 \%$ of the revenues to player $C$;

- In stage 4, player $C$ selects player B.

What is the gain of player $A$ ?

What is the gain of player $B$ ?

What is the gain of player $C$ ?

\section{Example 2. Suppose that:}

- In stage 1, player A choose to not commit himself to leaving a 50\% share of revenues to player $C$.

- In stage 2, player $C$ chooses to invest; 
- In stage 3, player A chooses to leave $70 \%$ of the revenues to player C; player B chooses to leave $80 \%$ of the revenues to player $C$;

- In stage 4, player $C$ selects player $A$.

What is the gain of player $A$ ?

What is the gain of player $B$ ?

What is the gain of player $C$ ? 


\section{phase VI}

The instructions for phase VI are identical to the instructions for phase VS, except for the computation of the gains of players A and B. For the record, these instructions detail the proceedings of each period. As only the computation of the gains of players $\mathrm{A}$ and $\mathrm{B}$ differs from that in phase VS, we will read this part only together. It corresponds to the text written in blue.

You keep the same role than in phase VS of the experiment. All your decisions are anonymous.

This phase is independent from phase VS. This phase consists in ten periods. We describe below the proceedings of phase VI.

Description of each period As in phase VS, at the beginning of each period, groups of three players are composed with one player A, one B and one C. These three players will interact throughout the period. The interactions of these three players create revenues. All the groups are anonymous: you will not know with whom you are playing.

During the ten periods of phase VI, players A and B interact only once: it is not possible that players A and B interact once more in phase VI. Players C are randomly affected to a player A and a player B: it is possible that a player $C$ interacts several times with a player A or a player B but it is not automatic.

As in phase VS, inside each group of three participants, each period consists in four stages:

- In stage 1, player A makes a decision. He chooses either to commit himself or to not commit himself to leaving a 50\% revenue share to player C. He must choose among the following two options:

- "I commit myself to leaving a 50\% revenue share" or

- "I do not commit myself".

If player A chooses to commit himself, he has no decision to make in stage 3. If he chooses to not commit himself, he has a decision to make in stage 3.

- In stage 2 , the choice of player A made in stage 1 is revealed to player C. Player C makes a first decision. He must choose between two options:

- "Invest" or

- "Not invest".

- In stage 3, the choices of player $A$ in stage 1 and of player $C$ in stage 2 are revealed to players A and B. Player A makes his decision if he chose not to commit himself in stage 1 (and has no decision to make otherwise). Player B makes his decision. When player A and B make a decision, they make it simultaneously and without 
consulting each other. Each of them must choose one among the following nine options, which correspond to a percentage of the total revenues they plan to leave to player C:

- $50 \%$ or

- $55 \%$ or

- $60 \%$ or

- $65 \%$ or

- $70 \%$ or

- $75 \%$ or

- $80 \%$ or

- $85 \%$ or

- $90 \%$.

- In stage 4 , the choices of players A and B in stage 2 are revealed to player C. Player $\mathrm{C}$ makes his decision. He must choose one of the two players $\mathrm{A}$ and $\mathrm{B}$ :

- "Player A " or

- "Player B".

How are the gains of each player computed in each period?

The gains of players A, B and C at each period depend on the choices of each of them. All the amounts reported in the following tables are in Euros.

\section{Gains of player C}

- The gain of player C is computed as in phase VS.

- The gain of player $\mathrm{C}$ depends on his investment decision and on the percentage of the revenues that will be left to him subsequently.

- This percentage of the revenues corresponds to the percentage of the revenues offered by the player A or B selected by player C in stage 4 .

The gain of player $C$ in each situation is displayed in the following table (this table is the same than in phase VS):

Gains of $C$

\begin{tabular}{lcccccccccc}
\hline \hline \multicolumn{2}{l}{ Percentage of revenues left to C } & $50 \%$ & $55 \%$ & $60 \%$ & $65 \%$ & $70 \%$ & $75 \%$ & $80 \%$ & $85 \%$ & $90 \%$ \\
\hline \multirow{2}{*}{ Choice of C } & Not invest & 10 & 12 & 13 & 14 & 16 & 17 & 19 & 20 & 22 \\
& Invest & 1 & 5 & 8 & 12 & 16 & 20 & 23 & 27 & 31 \\
\hline
\end{tabular}


Gains of players A and B The gains of players A and B are computed differently in phase VI compared to phase VS. The gains of players A and B depend from the percentage of the revenues that they offer to leave to player $C$ and from the choices of player $C$ (to invest or not, and player A or B).

- If player C chooses the offer of player $\mathrm{A}$ in stage 4:

- The gains of player A in each situation are displayed in the following table (this table is not the same than in phase VS);

- The gain of player B is $2 €$.

- If player C chooses the offer of player B in stage 4:

- The gains of player B in each situation are displayed in the following table (this table is not the same than in phase VS);

- The gain of player $\mathrm{A}$ is $2 €$.

Gains of A and B

\begin{tabular}{lcccccccccc}
\hline \hline Percentage of revenues left to C & $50 \%$ & $55 \%$ & $60 \%$ & $65 \%$ & $70 \%$ & $75 \%$ & $80 \%$ & $85 \%$ & $90 \%$ \\
\hline \multirow{2}{*}{ Choice of C } & Not invest & 15 & 13 & 12 & 10 & 9 & 7 & 6 & 4 & 3 \\
& Invest & 37 & 33 & 30 & 26 & 22 & 19 & 15 & 11 & 7 \\
\hline
\end{tabular}

In addition to the amount displayed above, player $\mathrm{A}$ also receives a guaranteed amount that depends on the investment choice made by $C$. Whether player $C$ selects $A$ or $B$ in stage 4, player A is certain to receive this guaranteed amount. This guaranteed amount is displayed in the following table:

Additional payoff for $\mathrm{A}$

\begin{tabular}{lll}
\hline \hline & Guaranteed amount \\
\hline \multirow{2}{*}{ Choice of C } & Not invest & 52 \\
& Invest & 29 \\
\hline
\end{tabular}

Example. Suppose that:

- In stage 1, player A chooses to not commit himself to leaving a 50\% revenue share to player C;

- In stage 2, player $C$ chooses to not invest;

- In stage 3, player A chooses to let a $85 \%$ share of revenue to player C; player B chooses to leave $55 \%$ share of the revenues to player $C$;

- In stage 4, player $C$ selects player $A$.

The gain of player $A$ is $4 €+52 €=56 €$. The gain of player $B$ is $2 €$. 
Information received by the players at the end of each period As in phase VS, at the end of each period, the screen displays the amount of the player's gain for this period. Each player learns only his gain for the current period; the gains of the other players are not displayed.

The screen also displays the decisions taken by all players during the period: the three players in each group are reminded of the choices of player $C$ in stage 2 and in stage 4 , the choice of player A in stage 1 and in stage 3 and the choice of player B in stage 3 .

Please read these instructions carefully. Before starting phase VI of this experiment, you will answer a few questions about these instructions. As soon as you will have correctly answered these questions, we will be able to start. 


\section{Questions about the instructions}

Please answer the following questions about the instructions

- The table of the gains of player A, apart from the guaranteed amount, is the same as in phase VS.

\section{TRUE $\square$ FALSE $\square$}

- The table of the gains of player B is the same as in phase VS. TRUE $\square \quad$ FALSE

- The table of the gains of player C is the same as in phase VS. TRUE $\square$ FALSE

- The guaranteed amount is received by player A and player B. TRUE $\square \quad$ FALSE $\square$

- Player A receives a guaranteed amount only if he is chosen by C in stage 4 . TRUE $\square$ FALSE $\square$

- The guaranteed amount received by player A depends on the investment choice by player $C$ in stage 2 .

TRUE $\square \quad$ FALSE $\square$

- If player A chose to commit himself to leaving player C a $50 \%$ revenue share in stage 1 , he may change this decision in stage 3 .

\section{TRUE $\square$ FALSE}

Example. Suppose that:

- In stage 1, player A chooses to commit himself to leaving a 50\% revenue share to player C;

- In stage 2, player $C$ chooses to not invest;

- In stage 3, player A has no decision to make because he committed himself to let a $50 \%$ share of revenue to player $C$; player $B$ chooses to leave $90 \%$ share of the revenues to player $C$;

- In stage 4 , player $C$ selects player $B$.

What is the gain of player $A$ ?

What is the gain of player $B$ ?

What is the gain of player $C$ ?

Example 2. Suppose that:

- In stage 1, player A choose to not commit himself to leaving a 50\% share of revenues to player $C$.

- In stage 2, player $C$ chooses to invest;

- In stage 3, player A chooses to leave 70\% of the revenues to player C; player B chooses to leave $80 \%$ of the revenues to player $C$;

- In stage 4 , player $C$ selects player $A$.

What is the gain of player $A$ ?

What is the gain of player $B$ ?

What is the gain of player $C$ ? 


\section{A.3 Instructions for the Sabotage treatment}

We present below the English translation of the instructions handed out and read to the subjects participating in the Sabotage treatment.

\section{Instructions Sabotage (English translation)}

You are about to participate to an experiment on decision-making. This experiment is realized jointly by the Econometrics Laboratory at Ecole Polytechnique, Toulouse School of Economics, and the INRA-ALISS Laboratory. During this session, you will be able to earn money. How much you will earn will depend on your decisions and also on the decisions taken by other participants with whom you will be interacting. In addition to this amount you will also receive a participation fee of 5 Euros. Your earnings will be paid cash at the end of the experiment, in a separate room for confidentiality reasons.

During the experiment, you have been randomly assigned to two separate rooms. Because there are many of you, in total 30 participants, we had to allocate you into two rooms. This allocation is purely random and has no relation to the decisions you have to make during the experiment. During the experiment you will have to interact with other participants in the same room as well as participants in the other room.

These instructions explain in detail what are the decision-making tasks you will have to make during the experiment, and how your payment is going to be computed. All the participants receive the same instructions, irrespective of the room they are allocated to.

The decisions you make during the experiment are anonymous.

If you have questions about the instructions, please raise your hand. We will answer your questions privately. Along the session, it is prohibited to communicate with each other, subject to being excluded from the session and not receiving any payment. We also require that you do not use your mobile phones. 


\section{Proceedings of the experiment}

At the beginning of this experiment, you will be attributed a role that you will keep throughout the experiment. The computer program assigns these roles randomly. 10 participants will be assigned the role $A, 10$ the role $B$ and 10 the role $C$. You will participate to two phases of 10 periods each. You will keep the same role for all the periods of the experiment. You will thus keep the same role for these two phases.

We present first the proceedings of the first phase. Once the first phase will be over, we will give you the instructions for the second phase. The two phases are independent from each other. At the end of the experiment, one period among the twenty periods will be randomly drawn by the computer; this will determine your payments for the experiment.

\section{phase VS}

This phase consists in ten periods. All your decisions are anonymous. We describe below the proceedings of phase1.

Description of each period At the beginning of each period, groups of three players are composed with one player A, one B and one C. These three players will interact throughout the period. The interactions of these three players create revenues. All the groups are anonymous: you will not know with whom you are playing.

During the ten periods of phase VS, players A and B interact only once: it is not possible that players A and B interact once more in phase VS. Players C are randomly affected to a player $A$ and a player B: it is possible that a player $C$ interacts several times with a player A or a player B but it is not automatic.

Inside each group of three participants, each period is composed of four stages:

- In stage 1, player $C$ makes a first decision. He must choose between two options:

- "Invest" or

- "Not invest".

- In stage 2 , the choice of player $\mathrm{C}$ in stage 1 is revealed to players $\mathrm{A}$ and $\mathrm{B}$. Players $\mathrm{A}$ and B make their decisions, simultaneously and without consulting each other. Each of them must choose one among the following nine options, which correspond to a percentage of the total revenues they plan to leave to player $\mathrm{C}$ :

- $50 \%$ or

- $55 \%$ or

- $60 \%$ or

- $65 \%$ or

- $70 \%$ or

- $75 \%$ or

- $80 \%$ or 
- $85 \%$ or

$-90 \%$.

- In stage 3, the choices of players A and B in stage 2 are revealed to player C. Player $\mathrm{C}$ makes a second decision. He must choose one of the two players A and B :

- "Player A " or

- "Player B" .

- In stage 4 , the choice made by player $C$ in stage 3 is revealed to players $A$ and $B$. If player $C$ has chosen player B in stage 3 , no player makes any decision in stage 4 . If player $\mathrm{C}$ has chosen player $\mathrm{A}$ in stage 3 , player $\mathrm{A}$ has to make a decision. He must choose between two options:

- "Use the option $\mathcal{S}^{\prime \prime}$ or

- "Not use the option $\mathcal{S}$ "

How are the gains of each player computed in each period?

The gains of players A, B and C at each period depend on the choices of all of them. All the amounts reported in the following tables are in euros.

Gains of player C The gains of player C depend on his investment decision and on the percentage of the revenues that will be left to him subsequently. This percentage of the revenues corresponds to the percentage of the revenues offered by the player $A$ or $B$ selected by player $C$ in stage 3 . If player $C$ has chosen player $A$, his gains also depend from the choice made by player $\mathrm{A}$ in stage 4 to adopt or not the option $\mathcal{S}$.

- If player $C$ chooses player B in stage 3, the gains of player $C$ in each situation are displayed in the following table:

Gains of C

\begin{tabular}{lcccccccccc}
\hline \hline Percentage of revenues left to C & $50 \%$ & $55 \%$ & $60 \%$ & $65 \%$ & $70 \%$ & $75 \%$ & $80 \%$ & $85 \%$ & $90 \%$ \\
\hline \multirow{2}{*}{ Choice of C } & Not invest & 10 & 12 & 13 & 14 & 16 & 17 & 19 & 20 & 22 \\
& Invest & 1 & 5 & 8 & 12 & 16 & 20 & 23 & 27 & 31 \\
\hline
\end{tabular}

- If player $\mathrm{C}$ chooses player $\mathrm{A}$ in stage 3 :

- The gains of player $C$ in each situation are also displayed in the above table whenever player A chooses not to use the option $\mathcal{S}$;

- The gains of player C are displayed in the following table whenever player A chooses to use the option $\mathcal{S}$.

Example: suppose that 
Gains of player C

\begin{tabular}{llc}
\hline \hline & If A chooses the option $\mathcal{S}$ & \\
\hline \multirow{2}{*}{ Choice of $C$} & Not invest & 11 \\
& Invest & 3 \\
\hline
\end{tabular}

- In stage 1, player $C$ chooses to not invest;

- In stage 2, player A chooses to leave $85 \%$ of the revenues to player C; Player B chooses to leave $55 \%$ of the revenues to player $C$;

- In stage 3, player $C$ selects player $A$.

- In stage 4, player A chooses not to use the option $\mathcal{S}$.

The gain of player $C$ for this period is $20 €$.

Gains of players A and B The gains of players A and B depend on the percentage of the revenues that they offer to leave to player $C$ and on the choices of player $C$ (to invest or not, and player A or B).

- If player C chooses the offer of player $\mathrm{A}$ in stage 3,

- The gains of player A depend on his choice to use or not the option $\mathcal{S}$ in stage 4:

* If player A chooses not to use the option $\mathcal{S}$, his gains in each situation are displayed in the following table;

* If player A chooses to use the option $\mathcal{S}$, it costs him $5 €$. His gains in each situation are the ones displayed in the following table minus $5 €$.

- The gain of player B is $2 €$.

- If player C chooses the offer of player B in stage 3:

- The gains of player B in each situation are displayed in the following table;

- The gain of player $A$ is $2 €$.

Gains of A or B

\begin{tabular}{lcccccccccc}
\hline \hline Percentage of revenues left to C & $50 \%$ & $55 \%$ & $60 \%$ & $65 \%$ & $70 \%$ & $75 \%$ & $80 \%$ & $85 \%$ & $90 \%$ \\
\hline \multirow{2}{*}{ Choice of C } & Not invest & 63 & 57 & 50 & 44 & 38 & 32 & 25 & 19 & 13 \\
& Invest & 74 & 67 & 59 & 52 & 44 & 37 & 30 & 22 & 15 \\
\hline
\end{tabular}

Example. Suppose that:

- In stage 1, player C chooses to not invest;

- In stage 2, player A chooses to leave $85 \%$ of the revenues to player C; Player B chooses to leave $55 \%$ of the revenues to player C; 
- In stage 3, player $C$ selects player $A$.

- In stage 4, player A chooses not to use the option $\mathcal{S}$.

The gain of player $A$ for this period is $19 €$. The gain of player $B$ for this period is $2 €$.

Information received by the players at the end of each period At the end of each period, the screen displays the amount of the player's gain for this period. Each player learns only his gain for the current period; the gains of the other players are not displayed.

The screen also displays the decisions taken by all players during the period: the three players in each group are reminded the choices of player $C$ in stage 1 and in stage 3 , the choices of players A and B in stage 2 and the choice of player A in stage 4 whenever player A has been selected by player $\mathrm{C}$ in stage 3 .

Please read these instructions carefully. Before starting phase VS of this experiment, you will answer a few questions about these instructions. As soon as you will have correctly answered these questions, we will be able to start.

Thanks for your participation! 


\section{Questions about the instructions}

Please answer the following questions about the instructions

- At the beginning of each period, groups of three participants consisting of one player A, one player B and one player C are constituted. TRUE $\square \quad$ FALSE $\square$

- A player A and a player B can be part of the same group several times during a given phase.

\section{TRUE $\square \quad$ FALSE $\square$}

- A player A and a player C can be part of the same group several times during a given phase.

\section{TRUE $\square \quad$ FALSE}

- A phase consists of 10 periods.

\section{TRUE $\square \quad$ FALSE $\square$}

- At the end of the experiment, one period among the 20 periods played is randomly drawn. Each participant will receive as a payment for the experiment the amount of his gains for this period, plus the participation fee of $5 €$.

\section{TRUE $\square \quad$ FALSE}

- At each period, the three players of one group learn their own gains and the gains of the two other players of their group.

TRUE $\square$ FALSE $\square$

- The gains of player A are reduced by $5 €$ if he chooses to use the option $\mathcal{S}$.

\section{TRUE $\square \quad$ FALSE}

\section{Example 1. Suppose that:}

- In stage 1, player $C$ chooses to not invest;

- In stage 2, player A chooses to leave $50 \%$ of the revenues to player C; player B chooses to leave $90 \%$ of the revenues to player $C$;

- In stage 3, player $C$ selects player $B$.

- In stage 4, no player makes a decision because player C has chosen player B in stage 3.

What is the gain of player $A$ ?

What is the gain of player $B$ ?

What is the gain of player $C$ ?

\section{Example 2. Suppose that:}

- In stage 1, player $C$ chooses to invest;

- In stage 2, player A chooses to leave $70 \%$ of the revenues to player C; player B chooses to leave $80 \%$ of the revenues to player $C$;

- In stage 3, player $C$ chooses player $A$.

- In stage 4, player A chooses to use the option $\mathcal{S}$.

What is the gain of player $A$ ?

What is the gain of player $B$ ?

What is the gain of player $C$ ? 


\section{phase VI}

The instructions for phase VI are identical to the instructions for phase VS, except for the computation of the gains of players A and B. For the record, these instructions detail the proceedings of each period. As only the computation of the gains of players $\mathrm{A}$ and $\mathrm{B}$ differs from that in phase VS, we will read this part only together. It corresponds to the text written in blue.

You keep the same role than in phase VS of the experiment. All your decisions are anonymous.

This phase is independent from phase VS. This phase consists in ten periods. We describe below the proceedings of phase VI.

Description of each period As in phase VS, at the beginning of each period, groups of three players are composed with one player A, one B and one C. These three players will interact throughout the period. The interactions of these three players create revenues. All the groups are anonymous: you will not know with whom you are playing.

During the ten periods of phase VI, players A and B interact only once: it is not possible that players A and B interact once more in phase VI. Players C are randomly affected to a player A and a player B: it is possible that a player $C$ interacts several times with a player A or a player B but it is not automatic.

As in phase VS, inside each group of three participants, each period consists in four stages:

- In stage 1, player $C$ makes a first decision. He must choose between two options:

- "Invest" or

- "Not invest".

- In stage 2 , the choice of player $\mathrm{C}$ in stage 1 is revealed to players A and B. Players A and B make their decisions, simultaneously and without consulting each other. Each of them must choose one among the following nine options, which correspond to a percentage of the total revenues they plan to leave to player $C$ :

- $50 \%$ or

- $55 \%$ or

- $60 \%$ or

- $65 \%$ or

- $70 \%$ or

- $75 \%$ or

- $80 \%$ or

- $85 \%$ or

$-90 \%$. 
- In stage 3, the choices of players A and B in stage 2 are revealed to player C. Player $\mathrm{C}$ makes a second decision. He must choose one of the two players A and B :

- "Player A " or

- "Player B" .

- In stage 4 , the choice made by player $C$ in stage 3 is revealed to players $A$ and $B$. If player $C$ has chosen player B in stage 3 , no player makes any decision in stage 4 . If player $\mathrm{C}$ has chosen player $\mathrm{A}$ in stage 3 , player $\mathrm{A}$ has to make a decision. He must choose between two options:

- "Use the option $\mathcal{S}^{\text {" or }}$

- "Not use the option $\mathcal{S}^{\prime}$

How are the gains of each player computed in each period?

The gains of players A, B and C at each period depend on the choices of each of them. All the amounts reported in the following tables are in Euros.

\section{Gains of player C}

- The gain of player C is computed as in phase VS.

- The gain of player $\mathrm{C}$ depends on his investment decision and on the percentage of the revenues that will be left to him subsequently.

- This percentage of the revenues corresponds to the percentage of the revenues offered by the player A or B selected by player C in stage 3.

- If player $\mathrm{C}$ has chosen player $\mathrm{A}$, his gains also depend from the choice made by player A in stage 4 to adopt or not the option $\mathcal{S}$.

If player $C$ chooses player B in stage 3 , the gain of player $C$ in each situation is displayed in the following table (this table is the same than in phase VS):

Gains of C

\begin{tabular}{llccccccccc}
\hline \hline Percentage of revenues left to C & $50 \%$ & $55 \%$ & $60 \%$ & $65 \%$ & $70 \%$ & $75 \%$ & $80 \%$ & $85 \%$ & $90 \%$ \\
\hline \multirow{2}{*}{ Choice of C } & Not invest & 10 & 12 & 13 & 14 & 16 & 17 & 19 & 20 & 22 \\
& Invest & 1 & 5 & 8 & 12 & 16 & 20 & 23 & 27 & 31 \\
\hline
\end{tabular}

If player $\mathrm{C}$ chooses player $\mathrm{A}$ in stage 3 :

- The gains of player $C$ in each situation are also displayed in the above table whenever player A chooses not to use the option $\mathcal{S}$;

- The gains of player $C$ are displayed in the following table whenever player A chooses to use the option $\mathcal{S}$. 
Gains of player C

\begin{tabular}{llc}
\hline \hline & If A chooses the option $\mathcal{S}$ & \\
\hline \multirow{2}{*}{ Choice of $C$} & Not invest & 11 \\
& Invest & 3 \\
\hline
\end{tabular}

Gains of players A and B The gains of players A and B are computed differently in phase VI compared to phase VS. The gains of players A and B depend from the percentage of the revenues that they offer to leave to player $C$ and from the choices of player $C$ (to invest or not, and player A or B).

- If player C chooses the offer of player A in stage 3:

- The gain of player A depend on his choice to use or not the option $\mathcal{S}$ in stage 4:

* If player A chooses not to use the option $\mathcal{S}$, his gains in each situation are displayed in the following table (this table is not the same as in phase VS) ;

* If player A chooses to use the option $\mathcal{S}$, this brings him a gain of $5 €$. His gains in each situation are those displayed in the following table plus $5 €$.

- The gain of player B is $2 €$.

- If player C chooses the offer of player B in stage 3:

- The gains of player B in each situation are displayed in the following table (this table is not the same than in phase VS);

- The gain of player $\mathrm{A}$ is $2 €$.

Gains of A and B

\begin{tabular}{lcccccccccc}
\hline \hline \multirow{2}{*}{ Percentage of revenues left to C } & $50 \%$ & $55 \%$ & $60 \%$ & $65 \%$ & $70 \%$ & $75 \%$ & $80 \%$ & $85 \%$ & $90 \%$ \\
\hline \multirow{2}{*}{ Choice of C } & Not invest & 15 & 13 & 12 & 10 & 9 & 7 & 6 & 4 & 3 \\
& Invest & 37 & 33 & 30 & 26 & 22 & 19 & 15 & 11 & 7 \\
\hline
\end{tabular}

In addition to the amount displayed above, player $\mathrm{A}$ also receives a guaranteed amount that depends on the investment choice made by $C$. Whether player $C$ selects $A$ or B in stage 3, player A is certain to receive this guaranteed amount. This guaranteed amount is displayed in the following table:

Additional payoff for $\mathrm{A}$

\begin{tabular}{lll}
\hline \hline & Guaranteed amount \\
\hline \multirow{2}{*}{ Choice of C } & Not invest & 52 \\
& Invest & 29 \\
\hline
\end{tabular}

Example. Suppose that: 
- In stage 1, player $C$ chooses to not invest;

- In stage 2, player A chooses to leave $85 \%$ of the revenues to player C; player B chooses to leave $55 \%$ of the revenues to player $C$;

- In stage 3, player $C$ selects player $A$.

- In stage 4, player A chooses not to use the option $\mathcal{S}$.

The gain of player $A$ for this period is $4 €+52 €=56 €$. The gain of player $B$ for this period is $2 €$.

Information received by the players at the end of each period As in phase VS, at the end of each period, players learn on the screen the amount of their gain for this period. Each player learns only his gain for the current period and the gain of the other players is not displayed.

The screen also displays the decisions taken by all players during the period: the three players in each group are reminded the choices of player $C$ in stage 1 and in stage 3 , the choices of players A and B in stage 2 and the choice of player A in stage 4 whenever player A has been selected by player $\mathrm{C}$ in stage 3 .

Please read these instructions carefully. Before starting phase VI of this experiment, you will answer a few questions about these instructions. As soon as you will have correctly answered these questions, we will be able to start. 


\section{Questions about the instructions}

Please answer the following questions about the instructions

- The table of the gains of player A, apart from the guaranteed amount, is the same as in phase VS.

\section{TRUE $\square \quad$ FALSE}

- The table of the gains of player B is the same as in phase VS.

\section{TRUE $\square \quad$ FALSE}

- The table of the gains of player C is the same as in phase VS.

TRUE $\square \quad$ FALSE $\square$

- The guaranteed amount is received by player A and player B.

TRUE $\square \quad$ FALSE

- Player A receives a guaranteed amount only if he is chosen by C in stage 3.

TRUE $\square$ FALSE $\square$

- The guaranteed amount received by player A depends on the investment choice by player $C$ in stage 1 .

TRUE $\square$ FALSE

- The gains of player A are reduced by $5 €$ if he chooses to use the option $\mathcal{S}$. TRUE $\square \quad$ FALSE $\square$

Example 1. suppose that:

- In stage 1, player $C$ chooses to not invest;

- In stage 2, player A chooses to leave $50 \%$ of the revenues to player $C$; player B chooses to leave $90 \%$ of the revenues to player $C$;

- In stage 3, player $C$ selects player B.

- In stage 4, no player makes any decision because player C has chosen player B in stage 3.

What is the gain of player $A$ ?

What is the gain of player $B$ ?

What is the gain of player $C$ ?

Example 2. Suppose that:

- In stage 1, player $C$ chooses to invest;

- In stage 2, player A chooses to leave $70 \%$ of the revenues to player C; player B chooses to leave $80 \%$ of the revenues to player $C$;

- In stage 3, player $C$ chooses player $A$.

- In stage 4, player A chooses to use the option $\mathcal{S}$.

What is the gain of player $A$ ?

What is the gain of player $B$ ?

What is the gain of player $C$ ? 


\section{B Departures from theory}

\section{B.1 Average deviation scores (periods 3 to 10)}

Table 16 reports the average deviation scores in both phases in the Baseline, Commitment and Sabotage treatments for the last eight periods of each session and phase (Periods 3 to 10), to account for potential learning effects. The results are qualitatively in line with those displayed in Table 11. In particular, the peak of departures in Sabotage under VI for $U_{B}$ subjects' share decisions and $D$ subjects' investment decisions are still observed.

Table 16: Average deviation scores (Periods 3 to 10)

\begin{tabular}{cccccc}
\hline \hline Treatment & Phase & $\sigma_{A}^{H}$ & $\sigma_{B}^{O}$ & $\sigma_{D}^{I}$ & $\sigma_{D}^{U}$ \\
\hline \multirow{2}{*}{ Baseline } & VS & & 0.20 & 0.16 & 0.06 \\
& VI & & 0.23 & 0.08 & 0.04 \\
\hline \multirow{2}{*}{ Commitment } & VS & 0.08 & 0.15 & 0.12 & 0.01 \\
& VI & 0.28 & 0.20 & 0.15 & 0.06 \\
\hline \multirow{2}{*}{ Sabotage } & VS & $0.07^{\mathrm{a}}$ & 0.12 & 0.06 & 0.10 \\
& VI & $0.19^{\mathrm{a}}$ & 0.53 & 0.49 & 0.20 \\
\hline
\end{tabular}

Note: ${ }^{\text {a }}$ For selected $U_{A}$.

\section{B.2 Departures from theory by $U_{A}$ in the share decision}

We consider here the departures from theory of $U_{A}$ subjects in their share decisions. Note first that in the Sabotage treatment, $U_{A}$ can offer any share in equilibrium when integrated. Furthermore, in the Commitment treatment, $U_{A}$ subjects who exert the commitment option have no other decision to make. Hence departures from theory in $U_{A}$ 's share decision are relevant only in the Baseline treatment, and in the Commitment treatment for subjects that did not exert the hold-up option. We define deviation score $\sigma_{A}^{O}$ as follows:

- $\sigma_{A}^{O}=1$ when $U_{A}$ chooses a share in $[50 \%, 75 \%], 1_{1}^{1}$

- $\sigma_{A}^{O}=0$ otherwise.

Table 17 reports the average deviation score $\sigma_{A}^{O}$ in both phases in the Baseline, Commitment and Sabotage treatments. The average values are reported for all periods (periods 1 to 10) in the first column and and, to account for potential learning effects, for the last eight periods of each session and phase (Periods 3 to 10) in the second column.

\footnotetext{
${ }^{1}$ As for $U_{B}{ }^{\prime}$ s shares decisions, we allow for small "trembles" (namely, up to 10 percentage points) around the equilibrium share and thus only consider larger deviations as departures from theory.
} 
Table 17: Average deviation scores $\sigma_{A}^{O}$

\begin{tabular}{cccc}
\hline \hline Treatment & Phase & P1 to P10 & P3 to P10 \\
\hline Baseline & VS & 0.21 & 0.16 \\
& VI & 0.20 & 0.18 \\
\hline Commitment & VS & $0.16^{\mathrm{b}}$ & $0.09^{\mathrm{b}}$ \\
(for non-committed $\left.U_{A}\right)$ & VI & $0.28^{\mathrm{b}}$ & $0.30^{\mathrm{b}}$ \\
\hline Note: $^{\mathrm{b}}$ : For non-commited $U_{A}$. & & &
\end{tabular}

Table 17 shows that the average value of this deviation score is about 0.2 in both phases of the Baseline treatment. In the Commitment treatment, it remains about the same (0.16) under VS, whereas it almost doubles (0.28) under VI. The deviation score of $U_{A}$ subjects is similar in magnitude to the scores observed for the share decisions made by $U_{B}$ in the same treatments and phases.

Table 18 shows that vertical integration has no marginal effect on $\sigma_{A}^{O}$ in the Baseline and in the Commitment treatment.

Table 18: Marginal effect of vertical integration on $\sigma_{A}^{0}$ (Probit model)

\begin{tabular}{lc}
\hline \hline & Model I \\
\hline Baseline & -0.007 \\
& $(0.049)$ \\
Commitment (for non-committed $\left.U_{A}\right)$ & 0.096 \\
& $(0.078)$ \\
\hline Note: standard errors are reported in parentheses. &
\end{tabular}

\section{B.3 Interplay between departures from theory}

We study the marginal effect of every $\sigma \in \Sigma \equiv\left\{\sigma_{A}^{H}, \sigma_{B}^{O}, \sigma_{D}^{I}\right\}$ on every subsequent $\sigma^{\prime} \in \Sigma$ in the same period. Note that we do not consider $D$ subjects' departures in the choice of supplier $\left(\sigma_{D}^{U}\right)$, because they are mostly observed in the Sabotage treatment under VI (see Table 11), where they constitute a prerequisite for an error in sabotage decisions and are therefore highly correlated with $\sigma_{A}^{H}$.

In order to identify such interplay in its purest form, we focus on pairs of decisions and restrict attention to situations in which the third decision did not depart from theory.

Tables 19 and 20 present, in the Commitment and Sabotage treatments, the interplays between $\sigma_{D}^{I}, \sigma_{B}^{O}$ and $\sigma_{A}^{H}$ under VS and VI, respectively. Note that, under VS, the few statistically significant effects either do not differ between the Commitment and Sabotage treatments, or rely on too few departures for a meaningful interpretation of the results. 
Table 19: Marginal effects on departures in subsequent decisions under VS

\begin{tabular}{|c|c|c|}
\hline & Commitment & Sabotage \\
\hline$\sigma_{D}^{I}$ on $\sigma_{B}^{O}$ & $\begin{array}{c}0.129^{*} \\
(0.067)\end{array}$ & \\
\hline$\sigma_{D}^{I}$ on $\sigma_{B}^{O}$ & & $\begin{array}{l}0.145^{*} \\
(0.078)\end{array}$ \\
\hline$\sigma_{A}^{H}$ on $\sigma_{D}^{I}$ & $\begin{array}{c}0.199^{* * *} \\
(0.066)\end{array}$ & \\
\hline$\sigma_{D}^{I}$ on $\sigma_{A}^{H}\left(\right.$ if $U_{A}$ selected and $\left.\sigma_{B}^{O}=0\right)$ & & $a$ \\
\hline$\sigma_{A}^{H}$ on $\sigma_{B}^{O}\left(\right.$ if $\left.\sigma_{D}^{I}=0\right)$ & $\begin{array}{c}0.093 \\
(0.082)\end{array}$ & \\
\hline$\sigma_{B}^{O}$ on $\sigma_{A}^{H}\left(\right.$ if $U_{A}$ selected and $\left.\sigma_{D}^{I}=0\right)$ & & $\begin{array}{l}-0.009 \\
(0.065)\end{array}$ \\
\hline
\end{tabular}

Table 20: Marginal effects on departures in subsequent decisions under VI

\begin{tabular}{lcc}
\hline \hline & Commitment & Sabotage \\
\hline$\sigma_{A}^{H}$ on $\sigma_{B}^{O}\left(\right.$ if $\left.\sigma_{D}^{I}=0\right)$ & $0.262^{* * *}$ & \\
& $(0.040)$ & \\
$\sigma_{B}^{O}$ on $\sigma_{A}^{H}$ (if $U_{A}$ is selected and $\left.\sigma_{D}^{I}=0\right)$ & & \\
& & \\
$\sigma_{A}^{H}$ on $\sigma_{D}^{I}$ & 0.034 & \\
& $(0.073)$ & -0.184 \\
$\sigma_{D}^{I}$ on $\sigma_{A}^{H}\left(\right.$ if $U_{A}$ is selected and $\left.\sigma_{B}^{O}=0\right)$ & & $(0.118)$ \\
& & \\
$\sigma_{D}^{I}$ on $\sigma_{B}^{O}\left(\right.$ if $\left.\sigma_{A}^{H}=0\right)$ & -0.014 & \\
$\sigma_{D}^{I}$ on $\sigma_{B}^{O}$ & $(0.026)$ & $0.175^{* * *}$ \\
& & $(0.059)$ \\
\hline
\end{tabular}

Notes: $a$. There is a single occurrence in which $\sigma_{I}^{D}=0, \sigma_{B}^{O}=1$ and $U_{A}$ is selected (the $U_{A}$ subject then deviated). Standard errors are reported in parentheses. ${ }^{* * *}$ represents significance at $1 \%$ level and $*$ at $10 \%$ level. We use Probit regressions and compute average marginal effects; we also control for session fixed effect and evaluate standard errors using clusters at the individual level. 


\section{Level- $k$ theory}

For simplicity, we assume that, for any level $k \geq 1$, every player believes that all the other players are of level $k-1$. We also assume that, when indifferent between several actions, players randomly choose every of these actions with equal probability.

\section{C.1 The Commitment game}

\section{C.1.1 Level-0}

Players play randomly:

- In stage $0, U_{A}$ commits himself to offering the lowest share with probability $1 / 2$.

- In stage $1, D$ invests with probability $1 / 2$.

- In stage $2, U_{A}$ (if not committed) and $U_{B}$ each select any of the 9 possible sharingrules with probability $1 / 9$.

- In stage 3, D selects each supplier with equal probability.

\section{C.1.2 Level-1}

From level-1 on, $D$ selects in stage 3 the supplier offering the larger share. From now on, we thus focus on the first three stages.

Stage 2. Suppliers anticipate a random selection by a level-0 $D$, and thus seek to offer the sharing rule that grants them the highest revenue; hence, $U_{A}$ (even if not committed) and $U_{B}$ both offer $50 \%$.

Stage 1. If $U_{A}$ has not committed himself in stage $0, D$ anticipates that both level-0 suppliers will offer a randomly chosen sharing rule. The probabilities that the best offer is a given sharing rule are presented in Table 21.

Table 21: Level-1, probability of receiving $s$ as best offer

\begin{tabular}{|c|c|c|c|c|c|c|c|c|c|}
\hline$S$ & $50 \%$ & $55 \%$ & $60 \%$ & $65 \%$ & $70 \%$ & $75 \%$ & $80 \%$ & $85 \%$ & $90 \%$ \\
\hline Probability & $\frac{1}{81}$ & $\frac{3}{81}$ & $\frac{5}{81}$ & $\frac{7}{81}$ & $\frac{9}{81}$ & $\frac{11}{81}$ & $\frac{13}{81}$ & $\frac{15}{81}$ & $\frac{17}{81}$ \\
\hline
\end{tabular}

Given these probabilities, $D$ invests:

- not investing would yield an expected payoff equal to

$$
\begin{aligned}
& 10+3 \times 12+5 \times 13+7 \times 14+9 \times 16 \\
& \frac{+11 \times 17+13 \times 19+15 \times 20+17 \times 22}{81}=\frac{1461}{81} \text {; }
\end{aligned}
$$


- by investing, she obtains instead

$$
\begin{aligned}
& \begin{array}{c}
1+3 \times 5+5 \times 8+7 \times 12+9 \times 16 \\
+11 \times 20+13 \times 23+15 \times 27+17 \times 31
\end{array}=\frac{1735}{81}>\frac{1461}{81} .
\end{aligned}
$$

If instead $U_{A}$ has committed himself in stage 0 , then $D$ anticipates that the best offer will be that of level- $0 U_{B}$, which can be any share with equal probability; her expected payoff is then the same, whether she invests or not:

- if she does not invest, her expected payoff is given by

$$
\frac{10+12+13+14+16+17+19+20+22}{9}=\frac{143}{9}
$$

- if she invests, her expected payoff is equal to

$$
\frac{1+5+8+12+16+20+23+27+31}{9}=\frac{143}{9} .
$$

She thus invests randomly.

Stage $0 . U_{A}$ anticipates a random supplier selection by a level-0 $D$ and thus wants to offer $50 \%$ but is indifferent between doing so in stage 2 or in stage $0 ; U_{A}$ thus commits himself to offering the lowest share with probability $1 / 2$.

Recap. Under both VS and VI:

- Stage $0 . U_{A}$ commits himself with probability $1 / 2$.

- Stage 1 . $D$ invests with probability 1 if $U_{A}$ did not commit, and with probability $1 / 2$ otherwise.

- Stage 2. Regardless of $D^{\prime}$ s investment, $U_{A}$ (even if not already committed to doing so) and $U_{B}$ (regardless of $U_{A}$ 's commitment decisions) both offer $50 \%$.

\section{C.1.3 Level-2}

From level-2 on, suppliers expect $D$ to select the larger share in stage 3.

Stage 2. Absent commitment, each supplier expects his level-1 rival to offer $50 \%$ no matter what; hence, the relevant choice is between offering $50 \%$ or $55 \%$ (which suffices to be selected for sure). Furthermore:

- Under VS, the gains from offering $55 \%$ are 67 in case of investment and 57 otherwise; the expected gains from offering $50 \%$ are instead respectively equal to:

$$
\frac{1}{2} \times 74+\frac{1}{2} \times 2=38<67 \text { and } \frac{1}{2} \times 63+\frac{1}{2} \times 2=32.5<57 .
$$


- Under VI (and ignoring the gain obtained through D1, which is fixed at this stage), the expected gains from offering $55 \%$ are 33 in case of investment and 13 otherwise; the expected gains from offering $50 \%$ are instead respectively equal to:

$$
\frac{1}{2} \times 37+\frac{1}{2} \times 2=19.5<33 \text { and } \frac{1}{2} \times 15+\frac{1}{2} \times 2=8.5<13 ;
$$

It follows that offering 55\% is the best response, under both VS and VI, and regardless of the investment decision.

Stage 1. D never invests, as she anticipates that the level-1 suppliers will not offer more than $50 \%$.

Stage $0 . U_{A}$ expects the level- $1 D$ to invest with probability $1 / 2$ in case of commitment and with probability 1 otherwise, and the level- $1 U_{B}$ to offer $50 \%$, regardless of $D^{\prime}$ s investment and of his own commitment decision.

Therefore, under VS:

- In the absence of commitment, $U_{A}$ expects $D$ to invest and select his offered share of $55 \%$; the associated gain is equal to 67 .

- Under commitment, $U_{A}$ expects $D$ to invest with probability $1 / 2$ and select his offered share of $50 \%$ with probability $1 / 2$; the associated expected gain is equal to:

$$
\frac{1}{2} \times\left(\frac{1}{2} \times 74+\frac{1}{2} \times 2\right)+\frac{1}{2} \times\left(\frac{1}{2} \times 63+\frac{1}{2} \times 2\right)=35.25<67 .
$$

Likewise, under VI:

- In the absence of commitment, $U_{A}$ expects again $D$ to invest and select his offered share of $55 \%$; the associated gain (including that of $D 1$ ) is now equal to $33+29=62$.

- Under commitment, $U_{A}$ expects again $D$ to invest with probability $1 / 2$ and select his offered share of $50 \%$ with probability $1 / 2$; the associated expected gain is now equal to:

$$
\frac{1}{2} \times\left(29+\frac{1}{2} \times 37+\frac{1}{2} \times 2\right)+\frac{1}{2} \times\left(52+\frac{1}{2} \times 15+\frac{1}{2} \times 2\right)=54.5<62 .
$$

It follows that $U_{A}$ never commits himself to offering $50 \%$.

Recap. Under both VI and VS:

- In stage $0, U_{A}$ does not commit himself.

- In stage $1, D$ never invests, regardless of $U_{A}{ }^{\prime}$ s commitment decision.

- In stage 2 , regardless of $D^{\prime}$ s investment, $U_{A}$ (if not committed) and $U_{B}$ (regardless of $U_{A}$ 's commitment decision) always offer $55 \%$. 


\section{C.1.4 Level-3}

Stage 2. In case of commitment, the same reasoning as before (for level-2) implies that, from level-3 on, $U_{B}$ always offers $55 \%$, regardless of $U_{A}$ 's commitment and $D^{\prime}$ s investment decisions.

Absent commitment, each supplier expects his level-2 rival to offer 55\%; hence, offering more than $60 \%$ or less than $55 \%$ constitute dominated strategies. Furthermore:

- Under VS, the expected gains from offering $60 \%$ are 59 in case of investment and 50 otherwise; the expected gains from offering 55\% are instead, respectively:

$$
\frac{1}{2} \times 67+\frac{1}{2} \times 2=34.5<59 \text { and } \frac{1}{2} \times 57+\frac{1}{2} \times 2=29.5<50 .
$$

- Under VI, the expected gains from offering $60 \%$ are 30 in case of investment and 12 otherwise; the expected gains from offering $55 \%$ are instead, respectively:

$$
\frac{1}{2} \times 33+\frac{1}{2} \times 2=17.5<30 \text { and } \frac{1}{2} \times 13+\frac{1}{2} \times 2=7.5<12 .
$$

It follows that offering $60 \%$ is the best response, under both VS and VI, and regardless of the investment decision.

Stage 1. $D$ does not invest: regardless of the commitment decision, $D$ anticipates that level-2 suppliers will never offer more than 55\%; hence, she does not invest.

Stage $0 . U_{A}$ expects the level-2 $D$ to never invest and the level-2 $U_{B}$ to always offer $55 \%$; committing to offering $50 \%$ would therefore have no impact on the investment decision but prevent $U_{A}$ from competing for $D 2$ (and for D1 under VS); as losing the competition for support yields the lowest possible upstream payoff (namely, 2), it follows that $U_{A}$ does not commit himself.

Recap. Under both VS and VI:

- In stage $0, U_{A}$ does not commit himself.

- In stage $1, D$ never invests, regardless of $U_{A}{ }^{\prime}$ s commitment decision.

- In stage 2 , regardless of $D^{\prime}$ s investment, $U_{A}$ and $U_{B}$ offer $60 \%$ in the absence of commitment, otherwise $U_{B}$ offers $55 \%$.

\section{C.1.5 Level-4}

Stage 2. $U_{B}$ offers $55 \%$ in case of commitment. In the absence of commitment, each supplier expects his level-3 rival to offer $60 \%$; offering more than $65 \%$ or less than $60 \%$ thus constitute dominated strategies. Furthermore: 
- Under VS, the expected gains from offering $65 \%$ are 52 in case of investment and 44 otherwise; the expected gains from offering $60 \%$ are instead respectively equal to:

$$
\frac{1}{2} \times 59+\frac{1}{2} \times 2=30.5<52 \text { and } \frac{1}{2} \times 50+\frac{1}{2} \times 2=26<44 .
$$

- Under VI, the expected gains from offering $65 \%$ are 26 in case of investment and 10 otherwise; the expected gains from offering $60 \%$ are instead, respectively:

$$
\frac{1}{2} \times 30+\frac{1}{2} \times 2=16<26 \text { and } \frac{1}{2} \times 12+\frac{1}{2} \times 2=7<10 .
$$

It follows that offering $65 \%$ is the best response, under both VS and VI, and regardless of the investment decision.

Stage 1. D never invests, regardless of the commitment decision, as she anticipates that level-3 suppliers will not offer more than $60 \%$.

Stage $0 . U_{A}$ expects the level-3 $D$ to never invest and the level-3 $U_{B}$ to offer $55 \%$ in case of commitment and $60 \%$ otherwise; committing himself would therefore have no impact on the investment decision but prevent $U_{A}$ from competing for D2 (and for D1 under VS); it follows that $U_{A}$ does not commit.

Recap. Under both VS and VI:

- In stage $0, U_{A}$ does not commit himself.

- In stage $1, D$ never invests, regardless of $U_{A}{ }^{\prime}$ s commitment decision.

- In stage 2 , regardless of $D^{\prime}$ s investment, $U_{A}$ and $U_{B}$ offer $65 \%$ in the absence of commitment, otherwise $U_{B}$ offers $55 \%$;

\section{C.1.6 Level-5}

Stage 2. $U_{B}$ offers $55 \%$ in case of commitment. In the absence of commitment, each supplier expects his level-4 rival to offer $65 \%$; hence, offering more than $70 \%$ or less than $65 \%$ constitute dominated strategies. Furthermore:

- Under VS, the expected gains from offering $70 \%$ are 44 in case of investment and 38 otherwise; the expected gains from offering $65 \%$ are instead respectively equal to:

$$
\frac{1}{2} \times 52+\frac{1}{2} \times 2=27<44 \text { and } \frac{1}{2} \times 44+\frac{1}{2} \times 2=23<38 .
$$

- Under VI, the expected gains from offering 70\% are 22 in case of investment and 9 otherwise; the expected gains from offering $65 \%$ are instead, respectively:

$$
\frac{1}{2} \times 26+\frac{1}{2} \times 2=14<22 \text { and } \frac{1}{2} \times 10+\frac{1}{2} \times 2=6<9
$$


It follows that offering 70\% is the best response, under both VS and VI, and regardless of the investment decision.

Stage 1. D never invests, regardless of the commitment decision, as she anticipates that level-4 suppliers will not offer more than $65 \%$.

Stage $0 . U_{A}$ expects the level-4 $D$ to never invest and the level- $4 U_{B}$ to offer $55 \%$ in case of commitment and $65 \%$ otherwise; committing himself would therefore have no impact on the investment decision but prevent $U_{A}$ from competing; it follows that $U_{A}$ does not commit.

Recap. Under both VS and VI:

- In stage $0, U_{A}$ does not commit himself.

- In stage $1, D$ never invests, regardless of $U_{A}{ }^{\prime}$ s commitment decision.

- In stage 2 , regardless of $D^{\prime}$ s investment, $U_{A}$ and $U_{B}$ offer $70 \%$ in the absence of commitment, otherwise $U_{B}$ offers $55 \%$;

\section{C.1.7 Level-6}

Stage 2. $U_{B}$ offers $55 \%$ in case of commitment. In the absence of commitment, each supplier expects his level-5 rival to offer $70 \%$; hence, offering more than $75 \%$ or less than $70 \%$ constitute dominated strategies. Furthermore:

- Under VS, the expected gains from offering $75 \%$ are 37 in case of investment and 32 otherwise; the expected gains from offering $70 \%$ are instead, respectively:

$$
\frac{1}{2} \times 44+\frac{1}{2} \times 2=23<37 \text { and } \frac{1}{2} \times 38+\frac{1}{2} \times 2=20<32 .
$$

- Under VI, the expected gains from offering 75\% are 19 in case of investment and 7 otherwise; the expected gains from offering $70 \%$ are instead, respectively:

$$
\frac{1}{2} \times 22+\frac{1}{2} \times 2=12<19 \text { and } \frac{1}{2} \times 9+\frac{1}{2} \times 2=5.5<7 \text {. }
$$

It follows that offering 75\% is the best response, under both VS and VI, and regardless of the investment decision.

Stage 1. Absent commitment, $D$ anticipates that level-5 suppliers will offer $70 \%$, and is thus indifferent between investing or not; hence, she invests with probability $1 / 2$. In case of commitment, $D$ anticipates that the level- $5 U_{B}$ will offer $55 \%$, and thus does not invest.

Stage $0 . U_{A}$ expects the level-5 $D$ to never invest and the level-5 $U_{B}$ to offer $55 \%$ in case of commitment and $70 \%$ otherwise; committing would therefore have no impact on the investment decision but prevent $U_{A}$ from competing; it follows that $U_{A}$ does not commit. 
Recap. Under both VS and VI:

- In stage $0, U_{A}$ does not commit himself.

- In stage $1, D$ invests with probability $1 / 2$ in the absence of commitment, otherwise she does not invest.

- In stage 2 , regardless of $D^{\prime}$ s investment, $U_{A}$ and $U_{B}$ offer $75 \%$ in the absence of commitment, otherwise $U_{B}$ offers $55 \%$.

\section{C.1.8 Level-7}

Stage 2. $U_{B}$ offers $55 \%$ in case of commitment. In the absence of commitment, each supplier expects his level- 6 rival to offer $75 \%$; hence, offering more than $80 \%$ or less than $75 \%$ constitute dominated strategies. Furthermore:

- Under VS, the expected gains from offering $80 \%$ are 30 in case of investment and 25 otherwise; the expected gains from offering $75 \%$ are instead, respectively:

$$
\frac{1}{2} \times 37+\frac{1}{2} \times 2=19.5<30 \text { and } \frac{1}{2} \times 32+\frac{1}{2} \times 2=17<25 .
$$

- Under VI, the expected gains from offering $80 \%$ are 15 in case of investment and 6 otherwise; the expected gains from offering $75 \%$ are instead, respectively:

$$
\frac{1}{2} \times 19+\frac{1}{2} \times 2=10.5<15 \text { and } \frac{1}{2} \times 7+\frac{1}{2} \times 2=4.5<6 .
$$

It follows that offering $80 \%$ is the best response, under both VS and VI, and regardless of the investment decision.

Stage 1. In the absence of commitment, $D$ anticipates that level-6 suppliers will offer $75 \%$, and thus invests. In case of commitment, $D$ anticipates that level- $6 U_{B}$ will offer $55 \%$, and thus does not invest.

Stage $0 . U_{A}$ expects the level- $6 U_{B}$ to offer $55 \%$ in case of commitment and $75 \%$ otherwise. Hence, under VS, $U_{A}$ does not commit himself, as this would prevent him from competing.

Under VI, if he commits, $U_{A}$ expects the level- $6 D$ not to invest, and to select $U_{B}$; the expected gain is $52+2=54$. In the absence commitment, $U_{A}$ expects the level-6 $D$ to invest with probability $1 / 2$ and accept his offered share of $80 \%$; the expected gain is therefore:

$$
\frac{1}{2} \times(29+15)+\frac{1}{2} \times(52+6)=51<54 .
$$

It follows that $U_{A}$ commits himself under VI.

\section{Recap.}


- In stage $0, U_{A}$ does not commit himself under VS, but does so under VI.

- In stage 1, under both VS and VI, D invests in the absence of commitment, otherwise she does not invest.

- In stage 2 , under both VS and VI, and regardless of $D^{\prime}$ 's investment, $U_{A}$ and $U_{B}$ offer $80 \%$ in the absence of commitment, otherwise $U_{B}$ offers $55 \%$.

\section{C.1.9 Level-8}

Stage 2. $U_{B}$ offers $55 \%$ in case of commitment. In the absence of commitment, each supplier expects his level-7 rival to offer $80 \%$; hence, offering more than $85 \%$ or less than $80 \%$ constitute dominated strategies. Furthermore:

- Under VS, the expected gains from offering $85 \%$ are 22 in case of investment and 19 otherwise; the expected gains from offering $80 \%$ are instead, respectively:

$$
\frac{1}{2} \times 30+\frac{1}{2} \times 2=16<22 \text { and } \frac{1}{2} \times 25+\frac{1}{2} \times 2=13.5<19 .
$$

- Under VI, the expected gains from offering $85 \%$ are 11 in case of investment and 4 otherwise; the expected gains from offering $80 \%$ are instead, respectively:

$$
\frac{1}{2} \times 15+\frac{1}{2} \times 2=8.5<11 \text { and } \frac{1}{2} \times 6+\frac{1}{2} \times 2=4 .
$$

It follows that suppliers offer $85 \%$ under VS, regardless of the investment decision, and under VI, in case of investment; under VI and in the absence of investment, suppliers randomize with equal probability between offering $80 \%$ or $85 \%$, and anticipate an expected upstream payoff of 4 .

Stage 1. In the absence of commitment, $D$ anticipates that level-7 suppliers will offer $80 \%$, and thus invests. In case of commitment, $D$ anticipates that level- $7 U_{B}$ will offer $55 \%$, and thus does not invest.

Stage $0 . U_{A}$ expects the level-7 $U_{B}$ to offer $55 \%$ in case of commitment and $80 \%$ otherwise. Hence, under VS, $U_{A}$ does not commit himself, as this would prevent him from competing.

Under VI, if he commits, $U_{A}$ expects the level-7 $D$ not to invest, and select $U_{B}$; the expected gain is therefore $52+2=54$. In the absence of commitment, $U_{A}$ expects the level-7 $D$ to invest and accept his offered share of either $80 \%$ or $85 \%$, yielding an expected payoff $29+4=33<54$. It follows that $U_{A}$ commits himself.

\section{Recap.}

- In stage $0, U_{A}$ does not commit himself under VS, but does so under VI. 
- In stage 1 , under both VS and VI, D invests in the absence of commitment, otherwise she does not invest.

- In stage $2, U_{B}$ offers $55 \%$ in case of commitment; in the absence of commitment, suppliers offer $85 \%$ under VS (regardless of the investment decision) and under VI in case of investment, and randomize between $80 \%$ and $85 \%$ with equal probability under VI in the absence of investment.

\section{C.1.10 Level-9}

Stage 2. $U_{B}$ offers $55 \%$ in case of commitment. In the absence of commitment:

- Regardless of the investment decision under VS, and in case of investment under VI, each supplier expects his level-8 rival to offer $85 \%$; hence; offering less than $85 \%$ constitutes a dominated strategy. Furthermore:

- Under VS, the expected gains from offering 90\% are 15 in case of investment and 13 otherwise; the expected gains from offering $85 \%$ are instead, respectively:

$$
\frac{1}{2} \times 22+\frac{1}{2} \times 2=12<15 \text { and } \frac{1}{2} \times 19+\frac{1}{2} \times 2=10.5<13
$$

- Under VI, in case of investment, the expected gain from offering $90 \%$ is 7 , whereas the expected gain from offering $85 \%$ is:

$$
\frac{1}{2} \times 11+\frac{1}{2} \times 2=6.5<7
$$

- Under VI and in the absence of investment, both suppliers expect the other, level-8 supplier to offer $80 \%$ and $85 \%$ with equal probability; hence, offering less than $80 \%$ constitute dominated strategies. Furthermore:

- the expected gain from offering $90 \%$ is 3 ;

- the expected gain from offering $85 \%$ is

$$
\frac{1}{2} \times 4+\frac{1}{2} \times\left(\frac{1}{2} \times 4+\frac{1}{2} \times 2\right)=3.5>3 ;
$$

- the expected gain from offering $80 \%$ is

$$
\frac{1}{2} \times\left(\frac{1}{2} \times 6+\frac{1}{2} \times 2\right)+\frac{1}{2} \times 2=3 .
$$

It follows that suppliers offer $90 \%$ under VS, regardless of the investment decision, and under VI in case of investment; by contrast, under VI and in the absence of investment, they only offer $85 \%$. 
Stage 1. In the absence of commitment, $D$ anticipates that level-8 suppliers will offer $85 \%$, and thus invests. In case of commitment, $D$ anticipates that the level- $8 U_{B}$ will offer $55 \%$, and thus does not invest.

Stage $0 . U_{A}$ expects the level- $8 U_{B}$ to offer $55 \%$ in case of commitment and at least $80 \%$ otherwise. Hence, under VS, $U_{A}$ does not commit himself, as this would prevent him from competing.

Under VI, in case of commitment $U_{A}$ expects the level-8 $D$ not to invest, and select $U_{B}$; the expected gain is therefore $52+2=54$. In the absence commitment, $U_{A}$ expects the level-8 $D$ to invest and accept his offered share of $90 \%$, yielding an expected payoff $29+7=36<54$. It follows that $U_{A}$ commits himself.

\section{Recap.}

- In stage $0, U_{A}$ does not commit himself under VS, but does so under VI.

- In stage 1, under both VS and VI, D invests in the absence of commitment, otherwise she does not invest.

- In stage $2, U_{B}$ offers $55 \%$ in case of commitment; in the absence of commitment, suppliers offer $90 \%$ under VS (regardless of the investment decision) and under VI in case of investment, and offer instead $85 \%$ under VI in the absence of investment.

\section{C.1.11 Level-10}

Stage 2. $U_{B}$ offers $55 \%$ in case of commitment. In the absence of commitment:

- Under VS, regardless of the investment decision, and under VI, in case of investment, each supplier expects his level-9 rival to offer $90 \%$; hence, offering less than $90 \%$ constitutes a dominated strategy.

- Under VI, in the absence of commitment and of investment, both suppliers expect the other, level-9 supplier to offer $85 \%$; hence, offering less than $85 \%$ constitutes a dominated strategy. Furthermore, the expected gain from offering $90 \%$ is 3 , which coincides with the expected gain from offering $85 \%$, given by:

$$
\frac{1}{2} \times 4+\frac{1}{2} \times 2=3
$$

It follows that suppliers offer $90 \%$ under VS, regardless of the investment decision, and under VI in case of investment; by contrast, under VI and in the absence of investment, they randomize with equal probability between offering $85 \%$ or $90 \%$.

Stage 1. In the absence of commitment, $D$ anticipates that level-9 suppliers will offer $90 \%$, and thus invests. In case of commitment, $D$ anticipates that level-9 $U_{B}$ will offer $55 \%$, and thus does not invest. 
Stage 0. From level-10 on:

- $U_{A}$ expects the level-9 $U_{B}$ to offer $55 \%$ in case of commitment and at least $85 \%$ otherwise. Hence, under VS, $U_{A}$ does not commit himself, as this would prevent him from competing.

- Under VI, in case of commitment $U_{A}$ expects the level-9 $D$ not to invest, and to select $U_{B}$; the expected gain is $52+2=54$. In the absence of commitment, $U_{A}$ expects the level-9 $D$ to invest and accept his offered share of $90 \%$ with probability $1 / 2$ (as the level-9 $U_{B}$ is expected to offer $90 \%$ as well); the expected payoff is thus:

$$
29+\frac{1}{2} \times 7+\frac{1}{2} \times 2=33.5<54 \text {. }
$$

It follows that $U_{A}$ commits himself under VI and does not do so under VS.

\section{Recap.}

- In stage $0, U_{A}$ does not commit himself under VS, but does so under VI.

- In stage 1, under both VS and VI, D invests in the absence of commitment, otherwise she does not invest.

- In stage $2, U_{B}$ offers $55 \%$ in case of commitment; in the absence of commitment, suppliers offer $90 \%$ under VS (regardless of the investment decision) and under VI in case of investment, and randomize instead with equal probability between offering $85 \%$ or $90 \%$ under VI in the absence of investment.

\section{C.1.12 Level-11}

As already noted, from level-10 on, in stage $0 U_{A}$ does not commit himself under VS, but does so under VI. From now on, we thus focus on stages 1 and 2.

Stage 2. $U_{B}$ offers $55 \%$ in case of commitment. In the absence of commitment:

- Under VS, regardless of the investment decision, and under VI, in case of investment, each supplier expects his level-10 rival to offer 90\%; hence, as in the previous round, they offer $90 \%$.

- Under VI, in the absence of investment, both suppliers expect the other, level-10 supplier to randomize with equal probability between offering $85 \%$ or $90 \%$; hence, offering less than $85 \%$ constitutes a dominated strategy. Furthermore, the expected gain from offering $90 \%$ is

$$
\frac{1}{2} \times 3+\frac{1}{2} \times\left(\frac{1}{2} \times 3+\frac{1}{2} \times 2\right)=2.75
$$


whereas that from offering $85 \%$ is

$$
\frac{1}{2} \times\left(\frac{1}{2} \times 4+\frac{1}{2} \times 2\right)+\frac{1}{2} \times 2=2.5<2.75 .
$$

It follows that suppliers offer $90 \%$ under both VS and VI, regardless of the investment decision.

Stage 1. In the absence of commitment, $D$ anticipates that level-10 suppliers will offer at least $85 \%$, and thus invests. In case of commitment, $D$ anticipates that the level-10 $U_{B}$ will offer $55 \%$, and thus does not invest.

\section{Recap.}

- In stage $0, U_{A}$ does not commit himself under VS, but does so under VI.

- In stage 1, under both VS and VI, D invests in the absence of commitment, otherwise she does not invest.

- In stage 2, under both VS and VI, and regardless of the investment decision, $U_{B}$ offers $55 \%$ in case of commitment and both suppliers offer $90 \%$ in the absence of commitment.

\section{C.1.13 Level-12 on}

We have:

- In stage $0, U_{A}$ does not commit himself under VS, but does so under VI.

- In stage 1:

- absent commitment, $D$ anticipates that level- $(k-1)$ suppliers will offer $90 \%$, and thus invests;

- in case of commitment, $D$ anticipates that the level- $(k-1) U_{B}$ will offer $55 \%$, and thus does not invest.

- In stage 2:

- absent commitment, each supplier expects his level- $(k-1)$ rival to offer $90 \%$, and responds by offering $90 \%$ as well;

- in case of commitment, as before $U_{B}$ offers $55 \%$. 


\section{C.1.14 Summary}

From level-1 on, $D$ selects in stage 3 the supplier offering the larger share. However, at level-1 the suppliers, anticipating a random selection from $D$, offer the lowest share, $50 \%$. From level-2 on:

- $D$ does not invest in case of commitment, as she expects $U_{B}$ to offer no more than $55 \%$ (specifically, 50\% when of level 1 and $55 \%$ otherwise).

- An independent $U_{A}$ never commits himself, as this would yield for sure the lowest possible payoff (2), whereas he can obtain a higher payoff with positive probability by (not committing and) either matching or outbidding $U_{B}$.

Furthermore, in the absence of commitment by $U_{A}$ :

- The suppliers offer a share that gradually increases: it reaches the investment indifference threshold $(70 \%)$ on level $5,(75 \%)$ on level 6 , and the maximal level $(90 \%)$ on level 9 under VS and/or in case of investment, and on level-11 under VI in case of no investment;

- In response, $D$ does not invest on levels 1 to 5 (expecting to obtain less than $70 \%$ from level- $(k-1)$ suppliers), randomizes between investing or not on level 6 (as she expects to obtain 70\% from level-5 suppliers), and invests from level 7 on (as she expects to obtain more than $70 \%$ from level- $(k-1)$ suppliers).

It follows that an integrated $U_{A}$ :

- Does not commit himself on levels 1 to 6 , as he expects to face a $D$ player who, being of level at most 5, will never invest anyway (and so committing himself brings no benefit for the subsidiary $D_{1}$, and prevents $U_{A}$ from competing with $U_{B}$ for $D$ );

- Commits himself from level 7 on, as $D$ (being of type at least 6) would otherwise invests with probability at least $1 / 2$, and $U_{B}$ (being also of type at least 6 ) will make a rather generous offer; hence, the benefit for the integrated subsidiary (equal to $(52-29) / 2=11.5$ when $D$ is of level-6, and $52-29=23$ when $D$ is of a higher level), which exceeds the expected difference in the bidding payoff (equal to $(1 / 2) \times$ $(15-2)+(1 / 2) \times(6-2)=8.5$ when $D$ is of level- 6 , and to no more than $11-2=$ 9 when $D$ is of a higher level).

It follows that, along the equilibrium path, from level-2 on:

- Under VS:

- $U_{A}$ never commits itself to offering a low share;

- the suppliers offer a share that gradually increases: it reaches $70 \%$ on level 5 , $75 \%$ on level 6 and $90 \%$ on level 9; 
- $D$ does not invest before level 6 , where she invests with probability $1 / 2$, and always invests from level 7 on.

- Under VI:

- before level-7, $U_{A}$ never commits himself and the two suppliers offer a share that gradually increases, reaching $70 \%$ on level-5 and $75 \%$ on level-6; $D$ never invests before level-6, where it does so with probability $1 / 2$.

- from level-7 on, $U_{A}$ commits himself to offering a low share, $D$ never invests, and $U_{B}$ offers $55 \%$.

\section{C.2 The Sabotage game}

\section{C.2.1 Level-0}

Players play randomly:

- In stage $1, D$ invests with probability $1 / 2$.

- In stage $2, U_{A}$ and $U_{B}$ each select any of the 9 possible sharing-rules with probability $1 / 9$.

- In stage 3, D selects each supplier with equal probability.

- In stage $4, U_{A}$ degrades his supply to $D$ with probability $1 / 2$ whenever he is selected by $D$.

\section{C.2.2 Level-1}

From level-1 on, in stage 4 , an integrated $U_{A}$ always degrades his support when selected by $D$, whereas an independent $U_{A}$ never does so. From now on, we will focus on stages 1 to 3 .

Stage 3. Under VS D selects the supplier offering the larger share; under VI, she selects the supplier offering the best deal, assuming that $U_{A}$ 's support will be degraded with probability $1 / 2$.

Stage 2. Suppliers anticipate a random selection by a level-0 $D$, and thus seek to offer the sharing rule that grants them the highest revenue; hence, both suppliers offer $50 \%$.

Stage 1. $D$ anticipates that that the level-0 $U_{A}$, if selected, will degrade his support with probability $1 / 2$. Hence, if she invests, her resulting expected payoffs, as a function of the suppliers' offers, are as in Table 22 . 
Table 22: Level-1, Expected payoff for $D$ (investment)

\begin{tabular}{|c|c|c|c|c|c|c|c|c|c|}
\hline$U_{A}^{\prime}$ 's offer & $50 \%$ & $55 \%$ & $60 \%$ & $65 \%$ & $70 \%$ & $75 \%$ & $80 \%$ & $85 \%$ & $90 \%$ \\
$D^{\prime}$ 's expected payoff & 2 & 4 & 5.5 & 7.5 & 9.5 & 11.5 & 13 & 15 & 17 \\
\hline$U_{B}{ }^{\prime}$ s offer & $50 \%$ & $55 \%$ & $60 \%$ & $65 \%$ & $70 \%$ & $75 \%$ & $80 \%$ & $85 \%$ & $90 \%$ \\
$D^{\prime}$ 's payoff & 1 & 5 & 8 & 12 & 16 & 20 & 23 & 27 & 31 \\
\hline
\end{tabular}

As $D$ expects that both suppliers will randomize their offers, her expected payoff is:

$$
\frac{1}{9} \times\left(\begin{array}{c}
20+23+27+31 \\
+\frac{8 \times 16+17}{9}+\frac{6 \times 12+13+15+17}{9} \\
+\frac{4 \times 8+9.5+11.5+13+15+17}{9} \\
+\frac{2 \times 5+5.5+7.5+9.5+11.5+13+15+17}{9} \\
+\frac{2+4+5.5+7.5+9.5+11.5+13+15+17}{9}
\end{array}\right)=\frac{1443}{81} .
$$

If instead $D$ does not invest, her expected payoffs are given by Table 23

Table 23: Level-1, Expected payoff for $D$ (no investment)

\begin{tabular}{|c|c|c|c|c|c|c|c|c|c|}
\hline$U_{A}$ 's offer & $50 \%$ & $55 \%$ & $60 \%$ & $65 \%$ & $70 \%$ & $75 \%$ & $80 \%$ & $85 \%$ & $90 \%$ \\
$D^{\prime}$ s expected payoff & 10.5 & 11.5 & 12 & 12.5 & 13.5 & 14 & 15 & 15.5 & 16.5 \\
\hline$U_{B}{ }^{\prime}$ s offer & $50 \%$ & $55 \%$ & $60 \%$ & $65 \%$ & $70 \%$ & $75 \%$ & $80 \%$ & $85 \%$ & $90 \%$ \\
$D^{\prime}$ s payoff & 10 & 12 & 13 & 14 & 16 & 17 & 19 & 20 & 22 \\
\hline
\end{tabular}

As $D$ expects that both suppliers will randomize their offers, her expected payoff is:

$$
\frac{1}{9} \times\left(\begin{array}{c}
17+19+20+22 \\
+\frac{8 \times 16+16.5}{9}+\frac{6 \times 14+15+15.5+16.5}{9} \\
+\frac{4 \times 13+13.5+14+15+15.5+16.5}{9} \\
+\frac{3 \times 12+12.5+13.5+14+15+15.5+16.5}{9} \\
+\frac{10.5+11.5+12+12.5+13.5+14+15+15.5+16.5}{9}
\end{array}\right)=\frac{1348}{81}<\frac{1443}{81} .
$$

It follows that $D$ invests.

Recap. Under both VS and VI:

- In stage $1, D$ invests.

- In stage 2, regardless of $D^{\prime}$ s investment, $U_{A}$ and $U_{B}$ offer $50 \%$. 
- In stage 3, D selects the supplier offering the best deal, assuming that $U_{A}{ }^{\prime}$ s support will be degraded with probability $1 / 2$.

\section{C.2.3 Level-2}

From level-2 on, all players anticipate that in stage 4 , an integrated $U_{A}$ always degrades his support when selected by $D$, whereas an independent $U_{A}$ never does so.

Stage 3. It follows from the above observation that, from level-2 on:

- under VS, D selects the supplier offering the higher share and randomizes when they offer the same share.

- under VI, $D$ selects $U_{A}$ whenever $U_{B}$ offers a $50 \%$ share and selects $U_{B}$ otherwise.

From now on, we will focus on stages 1 and 2.

Stage 2. Each supplier expects his level-1 rival to offer a 50\% share, and $D$ to anticipate that $U_{A}$ will use the sabotage option with probability $1 / 2$. Hence, $U_{A}$ offers a $50 \%$ share (as this suffices to win the competition for sure), whereas $U_{B}$ offers a $55 \%$ share (as this suffices to win, and offering $50 \%$ would induce the level-2 $D$ to select $U_{A}$ ).

Stage 1. D anticipates that the two level-1 suppliers will offer a $50 \%$ share (and that the level-1 $U_{A}$ will choose the sabotage option when integrated). As a result, $D$ does not invest.

Recap. Under both VS and VI:

- In stage $1, D$ does not invest.

- In stage 2 , regardless $D^{\prime}$ s investment, $U_{A}$ offers a $50 \%$ share and $U_{B}$ offers a $55 \%$ share.

\section{C.2.4 Level-3 on}

Under VI, from level-3 on:

- In stage 2 , both suppliers expect the level-2 $D$ to select $U_{A}$ whenever $U_{B}$ offers a $50 \%$ share and $U_{B}$ otherwise; hence $U_{B}$ offers a $55 \%$ share and $U_{A}$ offers any share.

- In stage 1 , anticipating that $U_{B}$ will offer a $55 \%$ share and that $U_{A}$ will offer a degraded support, $D$ does not invest.

We now turn to the case of vertical separation.

Stage 2. Under VS, from level-3 on both suppliers expect the level- $(k-1) D$ to select the higher offer; it follows from the analysis of the Commitment treatment that each supplier seeks to outbid his level- $(k-1)$ rival. Hence, regardless of $D^{\prime}$ s investment decision, we have: 
- level-3: $U_{A}$ offers a $60 \%$ share and $U_{B}$ offers a $55 \%$ share;

- level-4: $U_{A}$ offers a $60 \%$ share and $U_{B}$ offers a $65 \%$ share;

- level-5: $U_{A}$ offers a $70 \%$ share and $U_{B}$ offers a $65 \%$ share;

- level-6: $U_{A}$ offers a $70 \%$ share and $U_{B}$ offers a $75 \%$ share;

- level-7: $U_{A}$ offers a $80 \%$ share and $U_{B}$ offers a $75 \%$ share;

- level-8: $U_{A}$ offers a $80 \%$ share and $U_{B}$ offers a $85 \%$ share;

- level-9: $U_{A}$ offers a $90 \%$ share and $U_{B}$ offers a $85 \%$ share;

- level-10 on: both suppliers offer a $90 \%$ share.

Stage 1. Based on the above observations:

- on levels 3 to $5, D$ expects the level- $(k-1)$ suppliers to offer at most a $65 \%$ share; hence, she does not invest;

- on level-6, $D$ expects the level-5 $U_{A}$ to offer a $70 \%$ share for a non-degraded support, and the level- $5 U_{A}$ to offer $65 \%$; she thus invests with probability $1 / 2$;

- from level-7 on, $D$ expects the level- $(k-1)$ suppliers to offer at least $75 \%$ share, and she thus invests.

\section{C.2.5 Summary}

From level- 1 on, in stage 4 , an integrated $U_{A}$ always degrades his support when selected by $D$, whereas an independent $U_{A}$ never does so. As a result, from level- 2 on:

- Under VI, $D$ does not invest and $U_{B}$ offers a low share of $55 \%$, which $D$ accepts.

- Under VS, $D$ selects the supplier offering the higher share and, from level-3 on:

- suppliers gradually increase their offered shares: the better offer reaches $70 \%$ on level $5,75 \%$ on level 6 and $90 \%$ on level 9; both suppliers offer $90 \%$ from level 10 on;

- $D$ does not invest before level 6 , where she invests with probability $1 / 2$, and always invests from level 7 on. 


\section{Social preferences}

We provide here a proof of Proposition 1, presented in Appendix E.2. We denote D's type by $\theta \in\{O, P\}$, where $O$ stands for Optimistic and $P$ for Pessimistic. The proof consists of four lemmas; we first show that there is no separating equilibrium:

Lemma D.1 There is no separating equilibrium.

Proof. Recall that $D$ is willing to accept the lower share $s_{L}$ only when being pessimistic. Thus, in a separating equilibrium where $D^{\prime}$ s investment decision $\delta_{\theta}$ reveals her type $\theta$ (i.e., $\delta_{O} \neq \delta_{P}$ ), $U_{B}$ offers $s_{L}$ when $\theta=P$ and $s_{H}$ when $\theta=O$, and in both cases $D$ accepts the offer. As

$$
\min _{\delta}\left\{s_{H}(R+\delta \Delta)-\delta I\right\}=s_{H} R>s_{L} R=\max _{\delta}\left\{s_{L}(R+\delta \Delta)-\delta I\right\}
$$

It follows that a pessimistic $D$ then always benefits from behaving as an optimistic one, so as to obtain the higher share $s_{H}$, regardless of the investment behavior of the optimistic and pessimistic types, a contradiction.

Next, we show that there is no pooling equilibrium either:

Lemma D.2 There is no pooling equilibrium.

Proof. Suppose that $D$ makes the same investment decision, regardless of her type (i.e., $\delta_{O}=\delta_{P}$ ). In the continuation equilibrium, $U_{B}$ expects $D$ to be optimistic with probability $\lambda$ and pessimistic with probability $1-\lambda$. If $U_{B}$ offers $s_{H}$, then $D$ accepts the offer regardless of her type, and $U_{B}$ thus obtains a share $1-s_{H}$ of the revenue. If instead $U_{B}$ offers $s_{L}, D$ accepts the offer when she is pessimistic and rejects it otherwise; $U_{B}$ thus obtains an expected share of the revenue equal to $(1-\lambda)\left(1-s_{L}\right)$, which exceeds $1-s_{H}$ under (2). Hence, in equilibrium $U_{B}$ offers $s_{L}$, and $D$ does not invest (as a pessimistic $D$ could not profitably invest, regardless of whether she accepts $s_{L}$ or picks the outside option). However, an optimistic $D$ would benefit from investing (and then picking the outside option), a contradiction.

We now establish the existence of the semi-separating equilibrium identified by Proposition 1

Lemma D.3 There exists a semi-separating equilibrium in which:

- D invests with probability 1 when she is optimistic, and with probability $y^{*} \in(0,1)$ otherwise.

- $U_{B}$ offers $s_{L}$ with probability 1 when $D$ does not invest, and offers $s_{H}$ with probability $z^{*} \in(0,1)$ otherwise. 
Proof. Suppose that $D$ invests with probability 1 when she is optimistic, and with probability $y \in(0,1)$ otherwise. If $D$ does not invest, $U_{B}$ expects her to be pessimistic and thus finds it optimal to offer $s_{L}$. If instead $D$ invests, $U_{B}$ expects her to be optimistic with probability

$$
\hat{\lambda}(y)=\frac{\lambda}{\lambda+(1-\lambda) y} .
$$

If $U_{B}$ offers $s_{H}$, then $D$ accepts the offer regardless of her type, and $U_{B}$ thus obtains a share $1-s_{H}$ of the revenue. If instead $U_{B}$ offers $s_{L}$, then $D$ accepts the offer when she is pessimistic and rejects it otherwise, and $U_{B}$ thus obtains an expected share of the revenue equal to $[1-\hat{\lambda}(y)]\left(1-s_{L}\right)$. Hence, for $U_{B}$ to be indifferent between making either offer, the probability $y$ must be equal to $y^{*}$, given by (3). It is straightforward to check that $y^{*}$ is positive and increases with $\lambda$, and that (2) implies $y^{*}<1$.

Conversely, suppose that $U_{B}$ offers $s_{L}$ with probability 1 when $D$ does not invest, and $s_{H}$ with probability $z \in(0,1)$ otherwise. Consider first the investment decision of a pessimistic $D$. As $D$ then always accepts $U_{B}$ 's offer, not investing yields a revenue equal to $s_{L} R$, whereas investing yields an expected revenue given by $\left[z s_{H}+(1-z) s_{L}\right](R+\Delta)-$ $I$. Hence for a pessimistic $D$ to be indifferent between investing or not, the probability $z$ must satisfy:

$$
s_{L} R=\left[z s_{H}+(1-z) s_{L}\right](R+\Delta)-I,
$$

which amounts to $z=z^{*}$, given by (4). It is straightforward to check that (1) implies that $z^{*}$ is positive and strictly lower than 1 .

Finally, if $D$ is indifferent between investing or not when she is pessimistic, then she strictly prefers to invest when she is optimistic, as she then picks the more attractive outside option when being offered $s_{L} t^{2}$

Finally, we check that there is no other equilibrium:

Lemma D.4 The equilibrium characterized in lemma D.3 is the unique equilibrium.

Proof. Consider a candidate equilibrium in which $D$ invests with probability $y_{O}$ when she is optimistic, and with probability $y_{P}$ otherwise. Lemma D.3 identified a unique equilibrium among the candidates where $y_{O}=1$ and $y_{P} \in(0,1)$; furthermore, the case $\left\{y_{O}=1, y_{P}=0\right\}$ is discarded by Lemma D.1 and the case $y_{O}=y_{P}=1$ is discarded by Lemma D.2. Hence, without loss of generality, we can now focus on candidate equilibria in which $y_{O}<1$.

Suppose that $U_{B}$ offers $s_{H}$ with probability $z_{\delta}$ when observing $D^{\prime}$ s investment decision $\delta \in\{0,1\}$, and let $\hat{s}_{\theta}$ denotes $D^{\prime}$ s expected share when $U_{B}$ offers $s_{L}$, which is given by $s_{L}$

${ }^{2} D^{\prime}$ s indifference condition (5) amounts to $0=\phi \equiv\left[z^{*} s_{H}+\left(1-z^{*}\right) s_{L}\right](R+\Delta)-I-s_{L} R$, where:

$$
\frac{\partial \phi}{\partial s_{L}}=\Delta-z^{*}(R+\Delta)=\Delta-\frac{I-s_{L} \Delta}{s_{H}-s_{L}}>0,
$$

where the second equality stems from the definition of $z^{*}$ and the inequality from $I>s_{H} \Delta$. It follows that replacing $s_{L}$ with the higher expected share $x_{H} \hat{s}$ breaks the indifference in favor of investing. 
when $\theta=P$ and by $x_{H} \hat{s}$ when $\theta=O$. D's net return from investment is then given by:

$$
\psi\left(\hat{s}_{\theta} ; z_{0}, z_{1}\right) \equiv\left[z_{1} s_{H}+\left(1-z_{1}\right) \hat{s}_{\theta}\right](R+\Delta)-I-\left[z_{0} s_{H}+\left(1-z_{0}\right) \hat{s}_{\theta}\right] R,
$$

where:

$$
\frac{\partial \psi}{\partial \hat{s}_{\theta}}\left(\hat{s}_{\theta} ; z_{0}, z_{1}\right)=\Delta+z_{0} R-z_{1}(R+\Delta) .
$$

The working assumption $y_{H}<1$ requires $\psi\left(x_{H} \hat{s} ; z_{0}, z_{1}\right) \leq 0$, which amounts to:

$$
\begin{gathered}
{\left[z_{1} s_{H}+\left(1-z_{1}\right) x_{H} \hat{s}\right](R+\Delta)-I-\left[z_{0} s_{H}+\left(1-z_{0}\right) x_{H} \hat{s}\right] R \leq 0} \\
\Longleftrightarrow z_{1}(R+\Delta) \leq z_{0} R+\frac{I-x_{H} \hat{s} \Delta}{s_{H}-x_{H} \hat{s}} .
\end{gathered}
$$

Using $I<s_{H} \Delta$, this implies $z_{1}(R+\Delta)<z_{0} R+\Delta$, or:

$$
\frac{\partial \psi}{\partial \hat{s}_{\theta}}\left(\hat{s}_{\theta} ; z_{0}, z_{1}\right)>0
$$

As $\hat{s}_{P}=s_{L}<x_{L} \hat{s}=\hat{s}_{O}$, it follows that the working condition $y_{H}<1$, or $\psi\left(\hat{s}_{O} ; z_{0}, z_{1}\right) \leq 0$, implies $\psi\left(\hat{s}_{P} ; z_{0}, z_{1}\right)<0$ and, thus, $y_{L}=0$. From Lemma D.2. we must therefore have $y_{H}>0$. But then, when $D$ invests, $U_{B}$ expects her to be optimistic and thus finds it strictly optimal to offer $s_{H}$; this, in turn, would induce both types of $D$ to invest with probability 1 , a contradiction.

\section{E Robustness checks}

We provide here robustness checks for the regressions presented in the paper.

Model $I$ is the model used in the paper (we control for session fixed effects and we evaluate standard errors using clusters at the individual level). Additionally, we first control for risk aversion and IQ in two ways: Model II controls for the decision maker scores and Model $I I^{\prime}$ controls instead for the scores of all three players in the group. Second, to check for learning effects, Model III discards the first two periods of each phase. Third, because some $D$ subjects may interact more than once with $U_{A}$ or $U_{B}$ subjects during a session, Model $I V$ provides an additional check using clusters at the session level.

For each table, standard errors are reported in parentheses; ${ }^{* * *},{ }^{* *}$ and ${ }^{*}$ respectively represent significance at $1 \%, 5 \%$ and $10 \%$ levels. For binary variables, we use Probit regressions and compute average marginal effects: we first compute the marginal effect for each subject, before aggregating across subjects; see Williams (2012) for details of the method. For the shares offered and accepted, we use OLS regressions. 


\section{E.1 Impact of Vertical integration on subjects' behavior}

\section{E.1.1 D subjects}

\section{Investment decisions}

Table 24: Marginal effect of VI on investment (Probit model)

\begin{tabular}{lccccc}
\hline \hline & Model I & Model II & Model II & Model III & Model IV \\
\hline Baseline & $0.080^{* * *}$ & $0.082^{* * *}$ & $0.082^{* * *}$ & $0.080^{* *}$ & $0.080^{* * *}$ \\
& $(0.028)$ & $(0.028)$ & $(0.028)$ & $(0.031)$ & $(0.031)$ \\
Commitment & $-0.428^{* * *}$ & $-0.428^{* * *}$ & $-0.428^{* * *}$ & $-0.455^{* * *}$ & $-0.428^{* * *}$ \\
& $(0.031)$ & $(0.030)$ & $(0.030)$ & $(0.025)$ & $(0.060)$ \\
Sabotage & $-0.367^{* * *}$ & $-0.364^{* * *}$ & $-0.364^{* * *}$ & $-0.406^{* * *}$ & $-0.370^{* * *}$ \\
& $(0.055)$ & $(0.052)$ & $(0.052)$ & $(0.053)$ & $(0.098)$ \\
\hline
\end{tabular}

\section{Revenue sharing}

Table 25: Marginal effect of VI on the share accepted by $D$ (OLS model)

\begin{tabular}{lccccc}
\hline \hline & Model I & Model II & Model II' & Model III & Model IV \\
\hline Baseline & 0.600 & 0.600 & 0.600 & -0.229 & 0.600 \\
& $(0.553)$ & $(0.554)$ & $(0.515)$ & $(0.544)$ & $(0.681)$ \\
Commitment & $-20.117^{* * *}$ & $-20.117^{* * *}$ & $-20.117^{* * *}$ & $-21.417^{* * *}$ & $-20.117^{* *}$ \\
& $(1.282)$ & $(1.284)$ & $(1.294)$ & $(1.451)$ & $(3.547)$ \\
Sabotage & $-10.450^{* * *}$ & $-10.450^{* * *}$ & $-10.450^{* * *}$ & $-12.313^{* * *}$ & $-10.450^{* *}$ \\
& $(1.181)$ & $(1.183)$ & $(1.189)$ & $(1.189)$ & $(1.596)$ \\
\hline
\end{tabular}




\section{E.1.2 Suppliers}

\section{$U_{A}$ subjects}

Table 26: Marginal effect of VI on offered shares by $U_{A}$ (OLS model)

\begin{tabular}{lccccc}
\hline \hline & Model I & Model II & Model II' & Model III & Model IV \\
\hline Baseline & 0.983 & 0.983 & 0.983 & 0.250 & 0.983 \\
& $(0.993)$ & $(0.995)$ & $(1.010)$ & $(0.995)$ & $(1.527)$ \\
Commitment & $-22.583^{* * *}$ & $-22.583^{* * *}$ & $-22.583^{* * *}$ & $-24.042^{* * *}$ & $-22.583^{* *}$ \\
& $(2.688)$ & $(2.692)$ & $(2.682)$ & $(2.769)$ & $(2.449)$ \\
Sabotage & 0.217 & 0.217 & 0.217 & -1.083 & 0.217 \\
& $(1.100)$ & $(1.102)$ & $(1.079)$ & $(1.047)$ & $(1.620)$ \\
\hline
\end{tabular}

\section{$U_{B}$ subjects}

Table 27: Marginal effect of VI on offered shares by $U_{B}$ (OLS model) - Cluster at the individual level

\begin{tabular}{lccccc}
\hline \hline & Model I & Model II & Model II' & Model III & Model IV \\
\hline Baseline & -1.183 & -1.183 & -1.183 & -1.479 & -1.183 \\
& $(1.054)$ & $(1.056)$ & $(1.052)$ & $(1.102)$ & $(1.655)$ \\
Commitment & $-18.100^{* * *}$ & $-18.100^{* * *}$ & $-18.100^{* * *}$ & $-19.229^{* * *}$ & $-18.100^{* *}$ \\
& $(1.416)$ & $(1.418)$ & $(1.427)$ & $(1.666)$ & $(2.957)$ \\
Sabotage & $-13.633^{* * *}$ & $-13.633^{* * *}$ & $-13.633^{* * *}$ & $-14.979^{* * *}$ & $-13.633^{* *}$ \\
& $(1.823)$ & $(1.826)$ & $(1.832)$ & $(1.989)$ & $(2.457)$ \\
\hline
\end{tabular}

\section{E.2 Effect of $U_{A}$ 's commitment}

Table 28: Marginal effect of $U_{A}$ 's commitment (Probit and OLS models)

\begin{tabular}{lccccc}
\hline \hline & Model $I$ & Model II & Model II' & Model III & Model IV \\
\hline Investment & $-0.500^{* * *}$ & $-0.494^{* * *}$ & $-0.495^{* * *}$ & $-0.489^{* * *}$ & $-0.481^{* * *}$ \\
& $(0.015)$ & $(0.013)$ & $(0.013)$ & $(0.025)$ & $(0.021)$ \\
Share offered by $U_{B}$ & $-22.851^{* * *}$ & $-22.874^{* * *}$ & $-24.200^{* * *}$ & $-24.240^{* * *}$ & $-22.947^{* *}$ \\
& $(1.666)$ & $(1.657)$ & $(1.647)$ & $(1.876)$ & $(2.676)$ \\
Share accepted by $D$ & $-28.283^{* * *}$ & $-28.296^{* * *}$ & $-28.301^{* * *}$ & $-29.081^{* * *}$ & $-28.502^{* * *}$ \\
& $(0.951)$ & $(0.945)$ & $(0.991)$ & $(1.074)$ & $(2.250)$ \\
\hline
\end{tabular}




\section{E.3 Impact of vertical integration on departures from theory}

\section{E.3.1 Hold-up decisions $\left(\sigma_{A}^{H}\right)$}

Table 29: Marginal effect of VI on $\sigma_{A}^{H}$ (Probit model)

\begin{tabular}{lccccc}
\hline \hline & Model I & Model II & Model II & Model III & Model IV \\
\hline Commitment & $0.198^{* * *}$ & $0.200^{* * *}$ & $0.200^{* * *}$ & $0.195^{* * *}$ & $0.203^{* *}$ \\
& $(0.074)$ & $(0.073)$ & $(0.073)$ & $(0.073)$ & $(0.101)$ \\
Sabotage & 0.115 & 0.108 & 0.095 & 0.105 & 0.110 \\
& $(0.078)$ & $(0.071)$ & $(0.067)$ & $(0.071)$ & $(0.045)$ \\
\hline
\end{tabular}

E.3.2 Shared offered by $U_{A}\left(\sigma_{A}^{O}\right)$

Table 30: Marginal effect of VI on $\sigma_{A}^{O}$ (Probit model)

\begin{tabular}{lccccc}
\hline \hline & Model I & Model II & Model II' & Model III & Model IV \\
\hline Baseline & -0.007 & -0.004 & -0.004 & 0.028 & -0.010 \\
& $(0.049)$ & $(0.049)$ & $(0.048)$ & $(0.048)$ & $(0.091)$ \\
Commitment & 0.096 & 0.082 & 0.086 & $0.150^{* *}$ & $0.112^{* * *}$ \\
(for non-committed $\left.U_{A}\right)$ & $(0.078)$ & $(0.063)$ & $(0.063)$ & $(0.054)$ & $(0.020)$ \\
\hline
\end{tabular}

\section{E.3.3 Shares offered by $U_{B}\left(\sigma_{B}^{O}\right)$}

Table 31: Marginal effect of VI on $\sigma_{B}^{O}$ (Probit model)

\begin{tabular}{lccccc}
\hline \hline & Model I & Model II & Model II & Model III & Model IV \\
\hline Baseline & 0.038 & 0.038 & 0.039 & 0.022 & 0.037 \\
& $(0.052)$ & $(0.051)$ & $(0.052)$ & $(0.055)$ & $(0.078)$ \\
Commitment & 0.002 & 0.004 & 0.004 & 0.036 & 0.007 \\
& $(0.041)$ & $(0.041)$ & $(0.041)$ & $(0.048)$ & $(0.058)$ \\
Sabotage & $0.301^{* * *}$ & $0.300^{* * *}$ & $0.300^{* * *}$ & $0.373^{* * *}$ & $0.303^{* * *}$ \\
& $(0.058)$ & $(0.057)$ & $(0.057)$ & $(0.052)$ & $(0.050)$ \\
\hline
\end{tabular}




\section{E.3.4 Investment decisions $\left(\sigma_{D}^{I}\right)$}

Table 32: Marginal effect of VI on $\sigma_{D}^{I}$ (Probit model)

\begin{tabular}{lccccc}
\hline \hline & Model I & Model II & Model II & Model III & Model IV \\
\hline Baseline & $-0.080^{* * *}$ & $-0.082^{* * *}$ & $-0.082^{* * *}$ & $-0.080^{* *}$ & $-0.080^{* * *}$ \\
& $(0.028)$ & $(0.028)$ & $(0.028)$ & $(0.031)$ & $(0.031)$ \\
Commitment & 0.028 & 0.028 & 0.029 & 0.037 & 0.030 \\
& $(0.036)$ & $(0.035)$ & $(0.035)$ & $(0.033)$ & $(0.075)$ \\
Sabotage & $0.389^{* * *}$ & $0.391^{* * *}$ & $0.391^{* * *}$ & $0.392^{* * *}$ & $0.393^{* * *}$ \\
& $(0.044)$ & $(0.043)$ & $(0.043)$ & $(0.046)$ & $(0.080)$ \\
\hline
\end{tabular}

\section{E.3.5 Choice of supplier $\left(\sigma_{D}^{U}\right)$}

Table 33: Marginal effect of VI on $\sigma_{D}^{U}$ (Probit model)

\begin{tabular}{lccccc}
\hline \hline & Model I & Model II & Model II' & Model III & Model IV \\
\hline Baseline & $-0.024^{*}$ & $-0.025^{*}$ & $-0.024^{*}$ & -0.017 & $-0.024^{*}$ \\
& $(0.014)$ & $(0.014)$ & $(0.012)$ & $(0.016)$ & $(0.014)$ \\
Commitment & $0.043^{*}$ & $0.044^{*}$ & $0.044^{* *}$ & $0.057^{* * *}$ & 0.042 \\
& $(0.022)$ & $(0.023)$ & $(0.022)$ & $(0.022)$ & $(0.029)$ \\
Sabotage & $0.143^{* * *}$ & $0.141^{* * *}$ & $0.139^{* * *}$ & $0.109^{* * *}$ & $0.143^{* * *}$ \\
& $(0.039)$ & $(0.038)$ & $(0.037)$ & $(0.038)$ & $(0.035)$ \\
\hline
\end{tabular}

